\title{
可溶液加工给体-受体有机小分子太阳能电池材料研究进展
}

\author{
李在房 $a$ 彭 强*,a,b 和 平 $a$ 王艳玲 $a$ \\ 侯秋飞 ${ }^{a}$ 李本林 ${ }^{a}$ 田文晶 $*, c$ \\ ( ${ }^{a}$ 襄樊学院化学工程与食品科学学院 襄阳 441053) \\ ( ${ }^{b}$ 四川大学化学学院 成都 610064) \\ ( ${ }^{c}$ 吉林大学超分子结构与材料国家重点实验室 长春 130012)
}

\begin{abstract}
摘要 近年来, 有机小分子体异质结太阳能电池因其制备工艺简单、廉价、轻便及柔性等优点而备受关注. 理想的有 机小分子给体材料是提高有机太阳能电池光电转换效率的基础. 系统地综述了可溶液加工有机小分子太阳能电池给体 材料的研究进展，并对其发展趋势和应用前景做了展望.
\end{abstract}

关键词 可溶液加工; 有机小分子; 给体-受体; 太阳能电池; 进展

\section{Progress of Solution Processable Donor-Acceptor Organic Small Molecular Solar Cell Materials}

\author{
Li, Zaifang ${ }^{a} \quad$ Peng, Qiang ${ }^{*, a, b} \quad$ He, Ping ${ }^{a} \quad$ Wang, Yanling ${ }^{a}$ \\ Hou, Qiufei ${ }^{a} \quad$ Li, Benlin ${ }^{a} \quad$ Tian, Wenjing*,c \\ ( ${ }^{a}$ School of Chemical Engineering and Food Science, Xiangfan University, Xiangyang 441053) \\ ( ${ }^{b}$ College of Chemistry, Sichuan University, Chengdu 610064) \\ ( ${ }^{c}$ State Key Laboratory of Supramolecular Structure and Materials, Jilin University, Changchun 130012)
}

\begin{abstract}
In recent years, bulk heterojunction solar cells based on small organic molecules are received wide attention due to their simple preparation technique, low-cost, light weight and flexibility. The ideal donor material of organic small molecule is the basis for improving the power conversion efficiency of the organic solar cell. In this review, the research advances of solution processable small molecule donor materials are reviewed systematically, and the development tendency and prospects for future application are discussed.
\end{abstract}

Keywords solution processable; organic small molecule; donor-acceptor; solar cell; progress

随着煤、石油等化石能源的逐渐枯竭, 人类迫切需 要开发对环境友好的可再生能源. 太阳能由于具有清 洁、无污染、取之不尽、用之不竭等优点而备受人们关 注. 太阳能电池是太阳能利用的最有效的形式, 可将太 阳能直接转化为电能. 目前, 基于单晶硅的无机太阳能 电池的转换效率已达 $24 \%^{[1]}$, 但因其制备工艺繁杂、成 本高、环境污染严重、携带不方便、不易加工成柔性器 件，限制了其在实际生活中的应用. 相对于无机太阳能 电池而言, 有机体异质结太阳能电池由于制备工艺简
单、廉价、易于实现大面积制备及柔性等优点，近年来 成为世界范围内的研究热点 ${ }^{[2 \sim 4]}$. 依据活性层中给体材 料种类的不同, 有机体异质结太阳能电池又可分为聚合 物体异质结太阳能电池和有机小分子体异质结太阳能 电池两类. 在过去的十几年中, 人们对聚合物体异质结 太阳能电池的研究取得了显著的进展; 目前, 文献报道 的聚合物体异质结太阳能电池的最高光电转换效率已 达 7.4\% ${ }^{[5]}$. 最近, 美国 SOLARMER ENERGY, INC 公司 报道了其研究成果，他们制备的聚合物体异质结太阳能

\footnotetext{
*E-mail: qiangpengjohnny@yahoo.com

Received September 27, 2011; revised November 17, 2011; published online December 13, 2011.

Project supported by the National Natural Science Foundation of China (No. 20874035), the Program for New Century Excellent Talents in University (No. NCET-10-0170), the Yang Scientist of Jing Gang Zhi Xing (JGZX) Project of Jiangxi Province (No. 2008DQ00700) and the Scientific Research Foundation of Sichuan University (No. YJ2011025).

国家自然科学基金(No. 20802033)、教育部新世纪优秀人才支持计划(No. NCET-10-0170)、江西省青年科学家(井冈之星)培养对象计划(No. 2008DQ00700)和四川大学科研启动基金(No. YJ2011025)资助项目.
} 
电池的光电转换效率已高达 $8.13 \%$. 同聚合物相比较, 有机小分子具有明确的分子结构、固定的分子量、较高 的纯度和较好的重复性, 使其在有机太阳能电池中更加 受到人们的青睐 ${ }^{[6 ~ 19]}$. 尤其是给体-受体(D-A)型有机小 分子材料表现出较宽的吸收光谱、较好的空气稳定性、 易于调节的能级水平和光电性质, 已经成为有机太阳能 电池研究的新的增长点. 在最近几年的研究中, 人们通 过对分子结构的有效调节以及对器件制备的不断优化, 已经将有机小分子体异质结太阳能电池的光电转换效 率由最初的 $0.03 \%^{[9]}$ 提高到 $6.7 \%^{[20]}$, 为有机小分子体异 质结太阳能电池的工业化奠定了良好的基础. 本文综述 了各类可溶液加工 D-A 型有机小分子的设计、合成及其 在有机体异质结太阳能电池中的应用, 分析了这些小分 子材料所具备的特点, 在此基础上如何构建高性能的有 机小分子给体材料提出建议, 并对有机小分子给体材料 以及高性能有机小分子太阳能电池的发展方向进行了

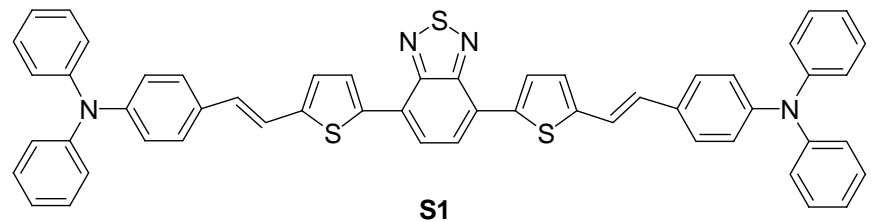

S1
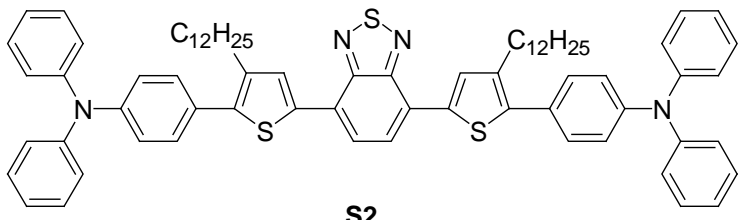

S2<smiles></smiles>

S3<smiles>CCCCCCc1cc(-c2ccc(-c3cc(CCCCCC)c(/C=C/c4ccc(N(c5ccccc5)c5ccccc5)cc4)s3)c3nsnc23)sc1/C=C/c1ccc(N(c2ccccc2)c2ccccc2)cc1</smiles>

S4

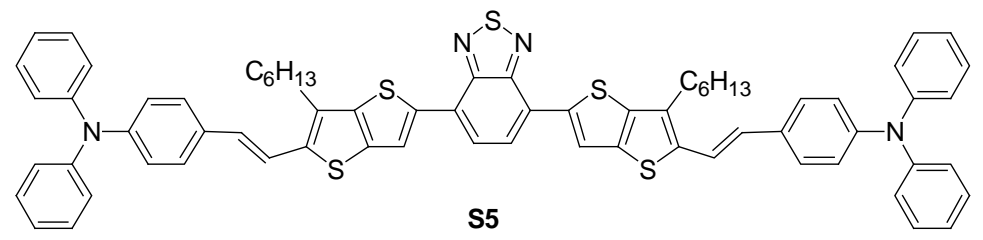<smiles>CCCCCCc1c(/C=C/c2ccc(N(c3ccc(OCCC)cc3)c3ccc(OCCC)cc3)cc2)sc2cc(-c3ccc(-c4cc5sc(/C=C/c6ccc(N(c7ccc(OCC(C)C)cc7)c7ccc(OCC(C)C)cc7)cc6)c(CCC)c5s4)c4nsnc34)sc12</smiles>

Chart 1 
的体异质结太阳能电池, 获得了 $0.26 \%$ 的光电转换效率. 在随后的研究工作中, 该小组 ${ }^{[25]}$ 通过对小分子 S1 化学 键种类的调节, 构建了新的小分子 S2 和 S3 (Chart 1), 以 $\mathrm{S} 2$ 为给体, $[6,6]$-苯基- $\mathrm{C}_{71}$-丁酸甲酯 $\left(\mathrm{PC}_{71} \mathrm{BM}\right)$ 为受体 制备的体异质结太阳能电池, 实现了 $1.23 \%$ 的光电转换 效率. 2011 年, 该小组 ${ }^{[26]}$ 通过将分子中的噻吩替换为具 有更强给电子能力和共平面性的并噻吩, 构建了小分子 S4 S6, 研究发现, 通过分子结构的改进, 有效拓宽了
材料的吸收光谱，其光电转化效率达到了 $1.44 \%$.

除了线型小分子外，李永舫小组在构建星型有机小 分子方面也开展了大量的研究工作. 2008 年，该小 组 ${ }^{[27,28]}$ 基于三苯胺和 $\mathrm{BT}$ 构建了星型小分子 S7 和 S8 (Chart 2), 分别获得了 $0.61 \%$ 和 $1.33 \%$ 的光电转化效率. 研究表明，星型小分子相对于线型小分子来说具有更 宽、更强的吸收光谱，更高的空穴迁移率以及更好的成<smiles></smiles><smiles>C(=C/c1ccc(/C=C/c2ccc(/C=C/c3ccc(N(c4ccc(/C=C/c5ccc(N(c6ccccc6)c6ccccc6)cc5)cc4)c4ccc(/C=C/c5ccc(/C=C/c6ccc(N(c7ccccc7)c7ccccc7)cc6)c6nsnc56)cc4)cc3)c3nsnc23)cc1)\c1ccc(/C=C/c2ccc(/C=C/c3ccc(N(c4ccccc4)c4ccccc4)cc3)c3nsnc23)cc1</smiles><smiles>CCCCCCc1csc(-c2ccc(/C=C/c3ccc(N(c4ccc(/C=C/c5ccc(-c6cc(CCCC)cs6)c6nsnc56)cc4)c4ccc(/C=C/c5ccc(-c6cc(CCCC)cs6)c6nsnc56)cc4)cc3)c3nsnc23)c1</smiles>

S9

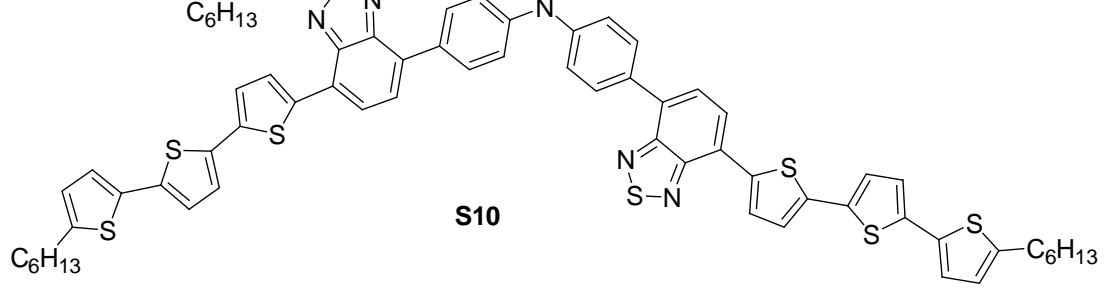

Chart 2 
膜性. 次年, 该小组 ${ }^{[29]}$ 通过将 D-A 型分子 S8 外围的三 苯胺单元更换为噻吩单元, 设计合成了星型小分子 $\mathbf{S 9}$ (Chart 2). 随着给电子基团的改变, 分子的光密度增加 了近 $20 \%$, 器件的 $J_{\mathrm{sc}}$ 得到了明显的提高, 光电转化效率 进一步提高到 2.39\%. 2011 年, 该小组 ${ }^{[14]}$ 对小分子 $\mathbf{S 9}$ 在 结构上进行了改进: 将分子内的双键改为单键, 并且将 分子外围的单噻吩单元替换为烷基化的三联噻吩, 由此 构建了新的星型小分子 S(TPA-BT-HTT) (S10). 研究发 现: 分子的空穴迁移率得到了明显的改善, HOMO 能级 进一步降低. 以 $\mathrm{S10}$ 为给体, $\mathrm{PC}_{71} \mathrm{BM}$ 为受体制备的体异 质结太阳能电池, 填充因子 $(\mathrm{FF})$ 为 0.52 , 光电转换效率 高达 $4.3 \%$, 这也是目前基于 BT 单元构建的可溶液加工 的 D-A 型小分子的最高光电转换效率.

2009 年, 中国科院学院化学研究所的薄志山小 组 ${ }^{[30]}$ 基于三苯胺、噻吩和 BT 单元分别构建了一系列可 溶液加工的线性和四臂星型小分子 S11 (Chart 3), 以 $\mathrm{S} 11$ 为给体, $\mathrm{PC}_{70} \mathrm{BM}$ 为受体制备的体异质结太阳能电 池, 实现了 $1.8 \%$ 的光电转换效率. 研究结果表明, 星型 分子较线型分子具有更优异的光电性能.
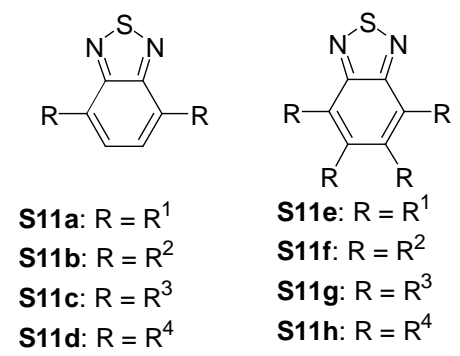

$$
\begin{aligned}
& \text { S11e: } R=R^{1} \\
& \text { S11f: } R=R^{2} \\
& \text { S11g: } R=R^{3}
\end{aligned}
$$$$
\text { S1lh: } R=R^{4}
$$
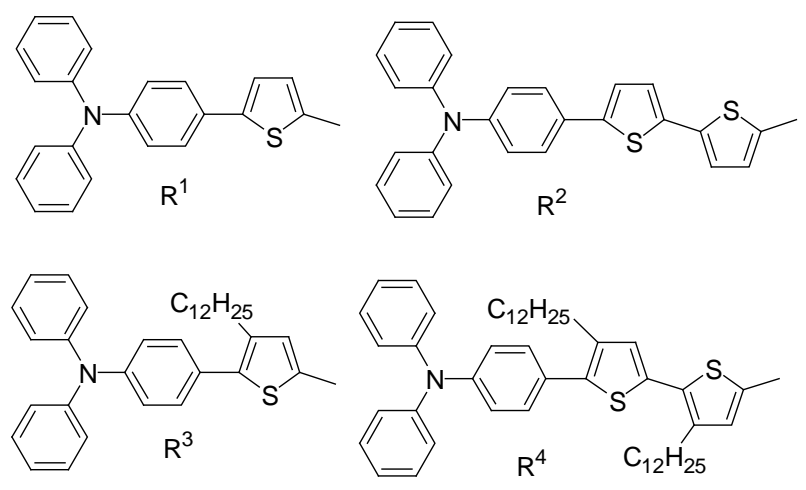

Chart 3

\section{2 氧基类给体-受体有机小分子}

氧基是一种很强的吸电子基团, 具有很高的电子亲 和势, 含有氰基的有机共轭分子在光电领域展现了优异 的性能 ${ }^{[31]}$. 研究发现, 分子中氧基的引入, 可以有效的 降低分子的 LUMO 能级, 增强分子的空气稳定性 ${ }^{[32]}$. 此 外, 氧基的引入还可以有效地降低分子的 HOMO 能级, 提升光伏器件的 $V_{\mathrm{oc}}{ }^{[33]}$. 在近年来的研究工作中, 氭基
被广泛地应用于构建 D-A 型有机共轭分子并应用到有 机太阳能电池 ${ }^{[9,33,34]}$. 以下根据分子中氧基种类的不同, 对含氧基有机小分子太阳能电池材料进行综述.

\section{1 基于单个氭基的给体-受体有机小分子}

基于氧基构建的 D-A 型有机小分子方面，希腊学者 Mikroyannidis 做了大量的研究工作. 2009 年, 该小组 ${ }^{[35]}$ 基于给电子基团苯、噻吩以及吸电子基团氧基和 $\mathrm{BT}$ 构 建了可溶液加工的小分子 S12 (Chart 4), 这些小分子材 料展现了较好的热稳定性、较低的 HOMO 能级和相对 较宽的吸收光谱, 获得了 $0.11 \%$ 的光电转换效率. 次年, 该小组 ${ }^{[36]}$ 基于给电子基团苯、噻吩以及吸电子基团氧基 和喹喔啉构建了线型小分子 S13. 新构建的小分子具有 较好的结晶性, 同时具有较宽的吸收光谱, 光学带隙仅 为 $1.59 \mathrm{eV}$. 以 $\mathrm{S} 13$ 为给体, $\mathrm{PC}_{61} \mathrm{BM}$ 为受体制备的体异 质结太阳能电池, 获得了 $2.21 \%$ 的光电转换效率, 经热
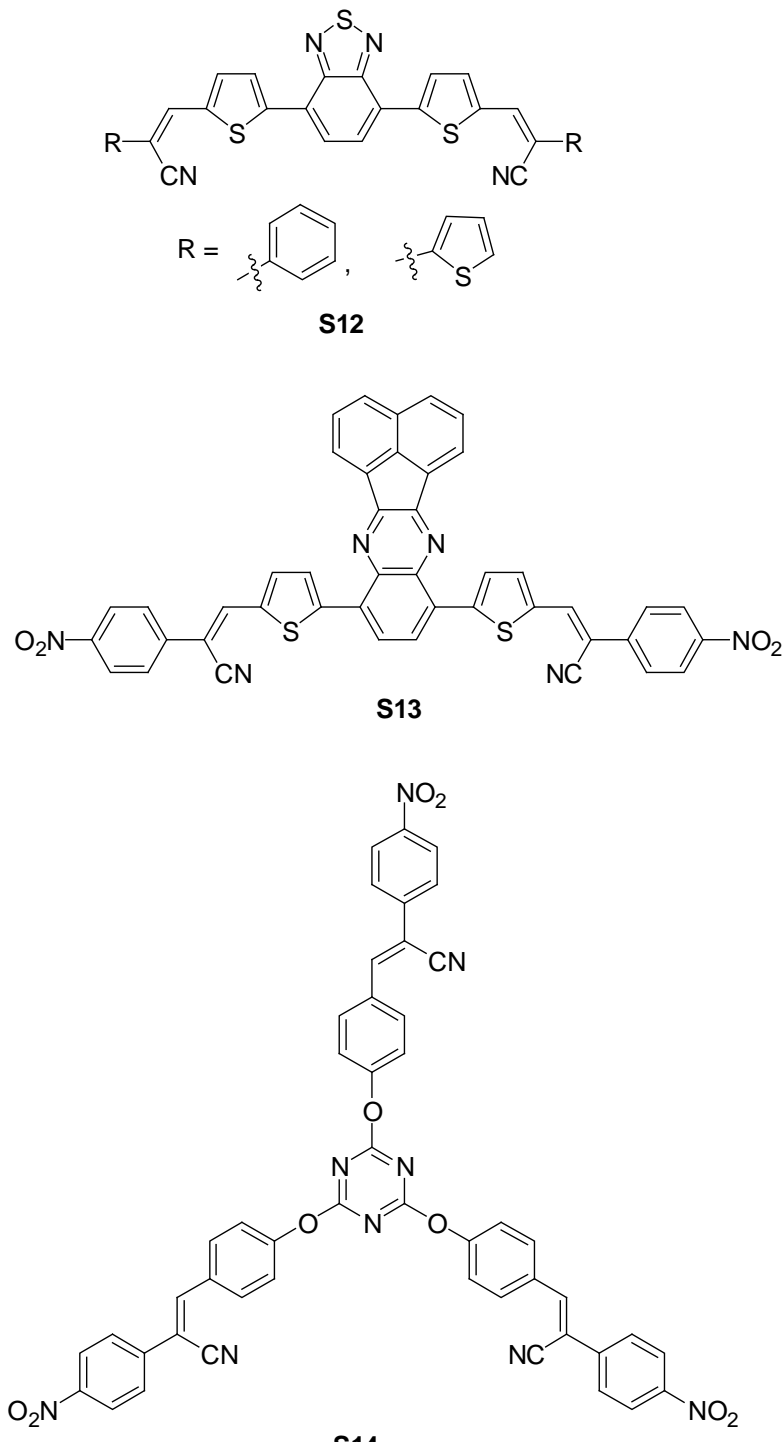

S14

Chart 4 
退火处理后, 器件的光电转化效率提高到 $3.23 \%$. 随后, 该小组基于给电子基团苯和吸电子基团氨基、三嗪构建 了星型给体小分子 S14 (Chart 4) ${ }^{[37]}$. 其光伏器件, 经热 退火处理后, 器件的光电转换效率高达 $3.82 \%$, 这也是 目前基于单氯基构建的可溶液加工有机小分子太阳能 电池的最高光电转换效率.

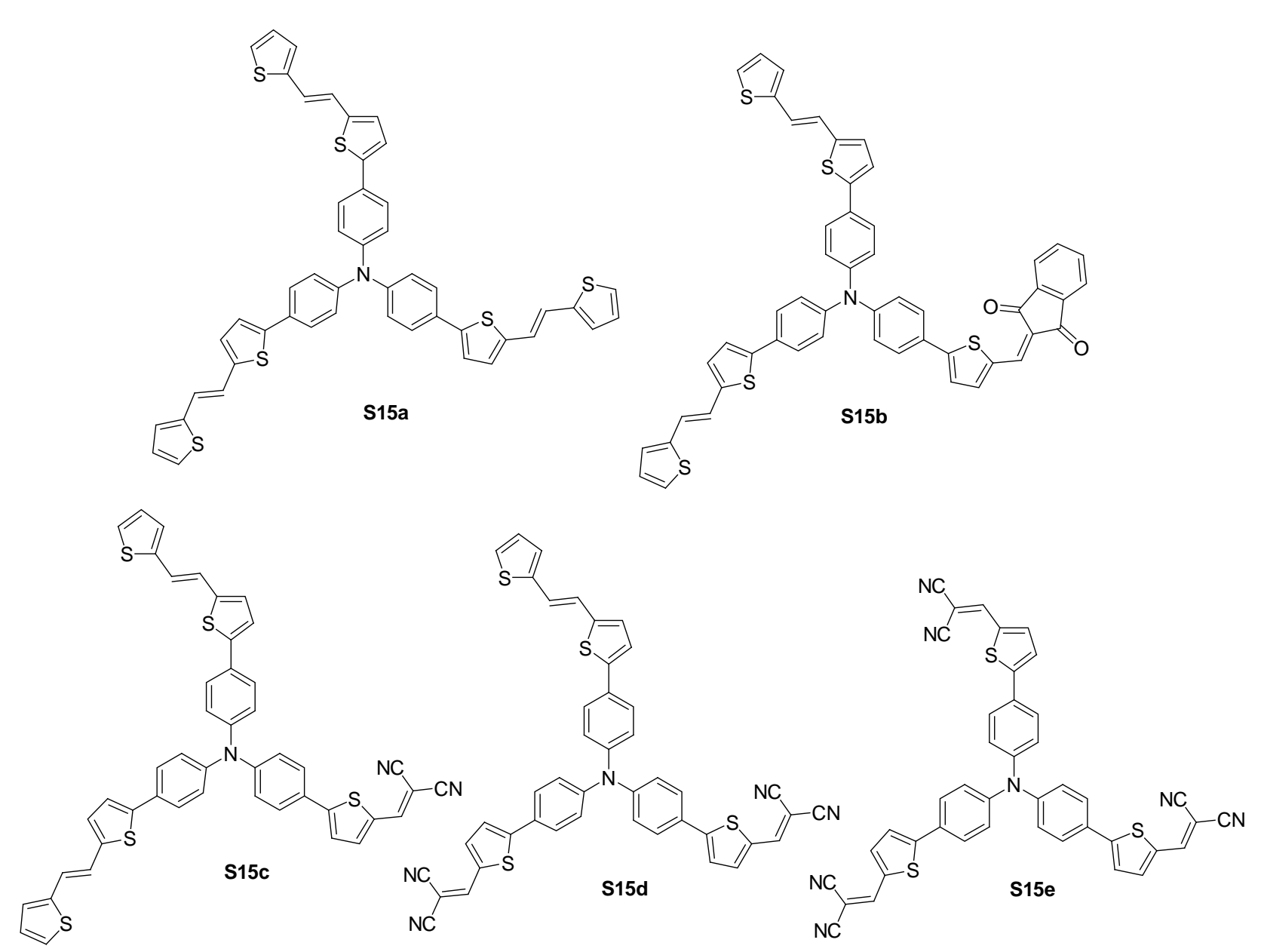

\section{2 基于丙二氧基的给体-受体有机小分子}

作为一种吸电子能力较强的基团，丙二氧基被广泛 应用于构建 D-A 型有机小分子. 2005 年, 法国里昂大学 的 Roncali 小组 ${ }^{[100]}$ 基于三苯胺、噻吩和丙二氧基构建了 一系列星型有机小分子 S15 (Chart 5), 首次系统研究了

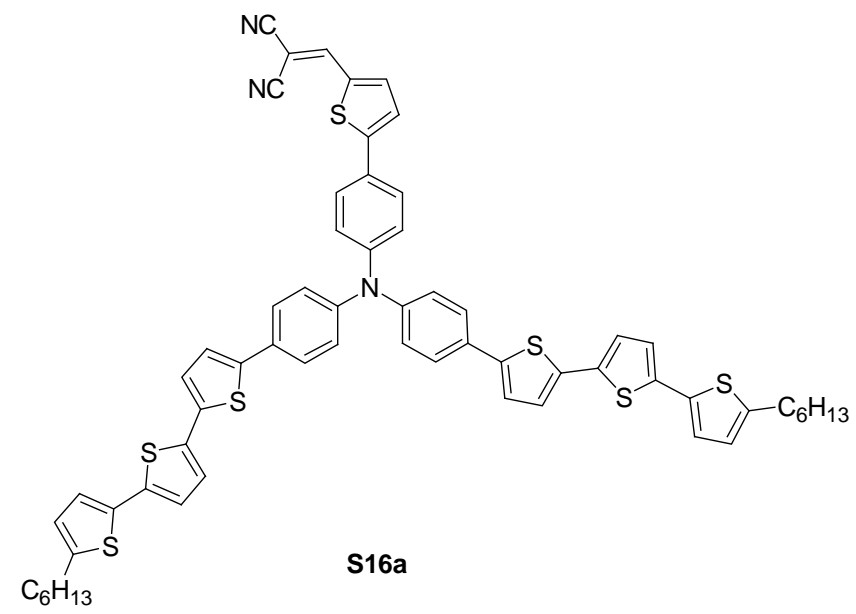<smiles>CCCCc1ccc(-c2ccc(-c3ccc(-c4ccc(N(c5ccc(-c6ccc(C=C(C#N)C#N)s6)cc5)c5ccc(-c6ccc(-c7ccc(C=C(C#N)C#N)s7)s6)cc5)cc4)s3)s2)s1</smiles>

Chart 5 
这类 D-A 型有机小分子中电荷转移强度对分子性能的 影响. 研究发现, 分子中丙二氧基数目的增加增强了分 子内电荷转移的程度, 有效拓宽了分子的吸收光谱, 大 大降低了分子的 HOMO 能级, 增强了分子的空气稳定 性. 光伏器件研究结果表明, 分子内吸电子基团数目的 增加, 提高了器件的 $V_{\mathrm{oc}}$, 改善了器件的光电转换效率. 最近, 该小组 ${ }^{[106]}$ 通过在分子中引入烷基化的齐聚噻吩, 构建了新的可溶液加工星型 D-A 型小分子 S16 (Chart 5), 其中基于小分子 $\mathbf{S 1 6 b}$ 和 $\mathrm{PC}_{61} \mathrm{BM}$ 制备的体异质结太 阳能电池, 光电转换效率为 $2.02 \%, V_{\mathrm{oc}}$ 为 $1.07 \mathrm{~V}$, 这也 是目前体异质结太阳能电池的最高 $V_{\mathrm{oc}}$.

2008 年, 香港浸会大学的 Wong 小组 ${ }^{[38 a]}$ 基于给电 子基团齐聚噻吩、二苯胺芴基和吸电子基团丙二氧基构 建了一系列可溶液加工的小分子 S17 和 S18 (Chart 6). 这些小分子材料均展现了非常好的热稳定性以及非常 宽的光谱吸收, 随着分子中噻吩链的增加, 给电子能力
的增强, 分子的光学带隙得到了降低. 以 S16 为给体, $\mathrm{PC}_{61} \mathrm{BM}$ 为受体制备的体异质结太阳能电池, 实现了 $1.72 \%$ 的光电转换效率. 最近, 该小组基于咔唑、齐聚噻 吩和丙二氧基构建了树状分子 S19 和 S20 (Chart 6) ${ }^{[38 b]}$. 随着分子中树枝的增多, 器件的性能得到了一定程度的 提高, 说明分子中树枝单元的增加, 可以有效地改善器 件的光电转换效率.

2011 年, 李永舫小组 ${ }^{[39]}$ 基于三苯胺、齐聚噻吩和丙 二氧基构建了新的星型分子 S21 和 S22 (Chart 7); 通过 在分子中引入共轭性更强的双键, 大大拓宽了分子的吸 收光谱，增强了分子吸收太阳光子的能力，同时也将分 子的光电转换效率由 $1.4 \%$ 提高到 $3.0 \%$.

2010 年, 陈永胜小组 ${ }^{[40 ~ 42]}$ 基于齐聚噻吩和丙二氭 基构建了一系列可溶液加工的受体-给体-受体(A-D-A) 型的小分子 S23, S24 和 S25 (Chart 8). 这些小分子具有

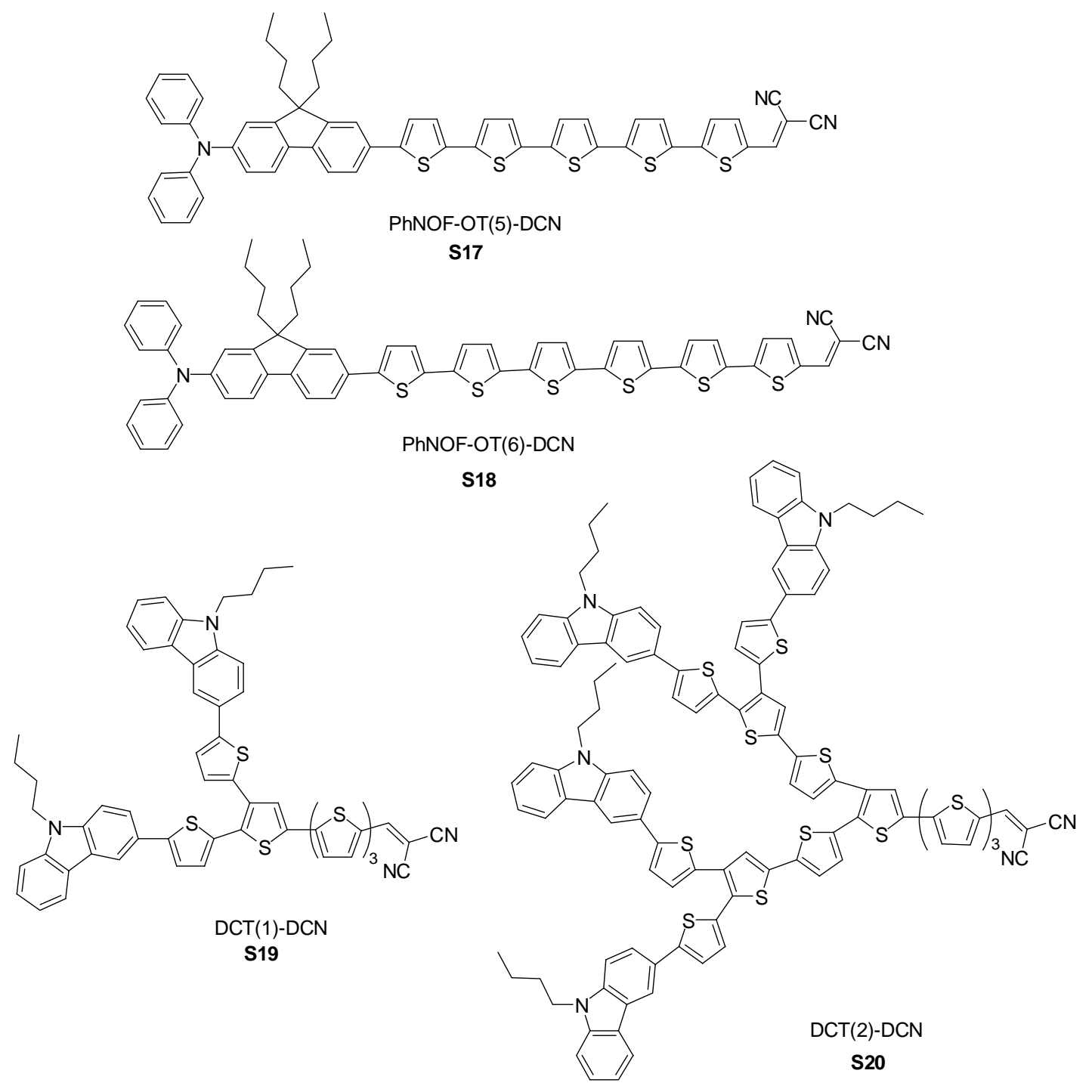

Chart 6 


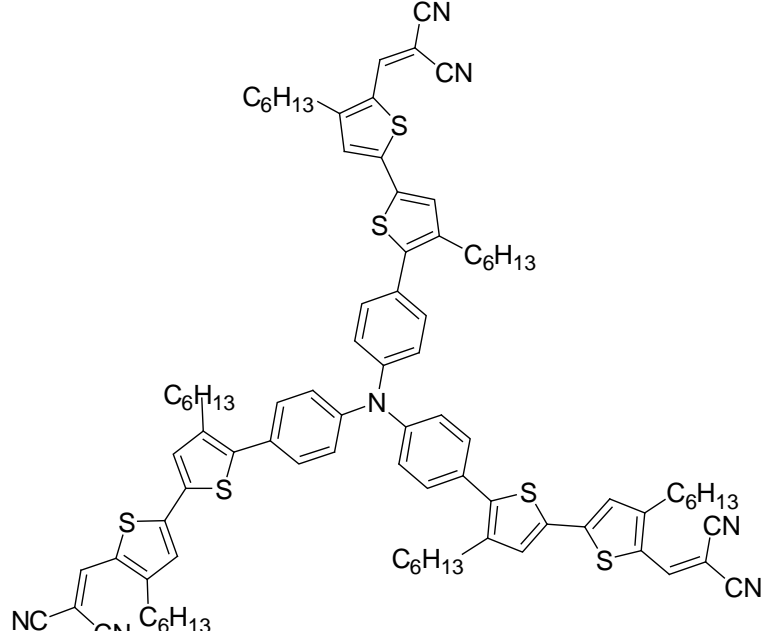

S(TPA-bTV-DCN)

S21

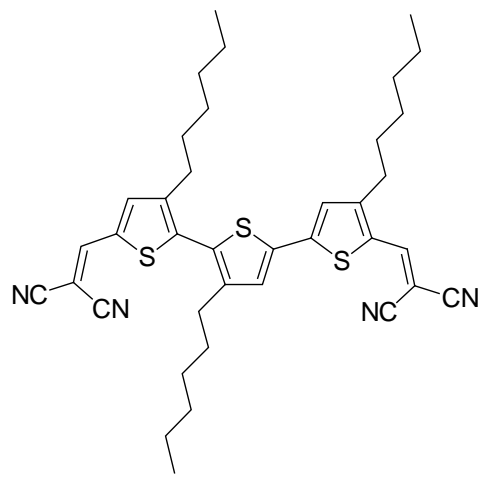

S23

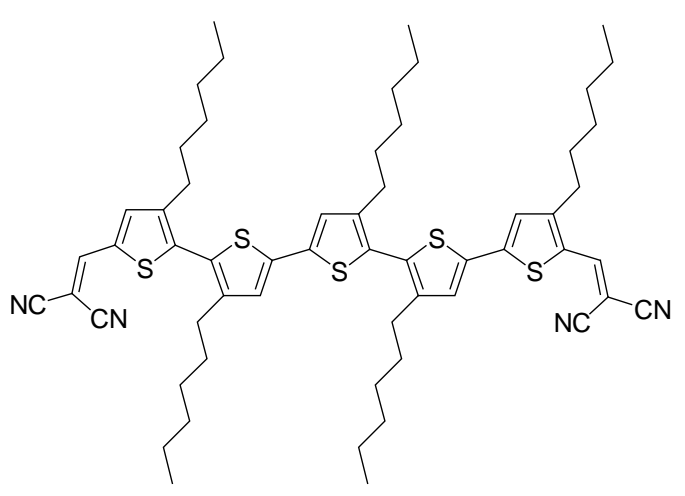

S24

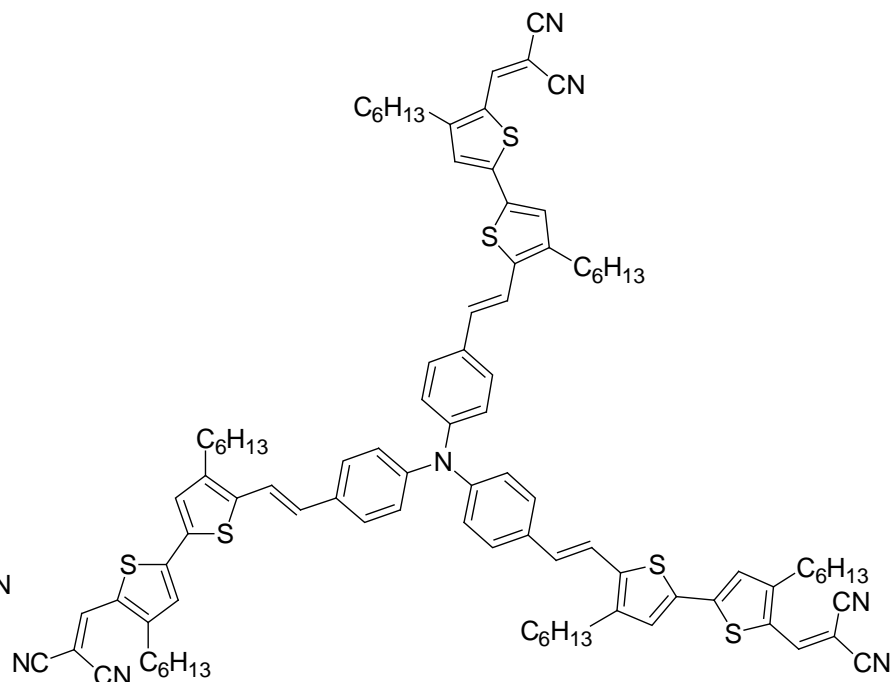

S(TPA-bT-DCN)

S22

Chart 7

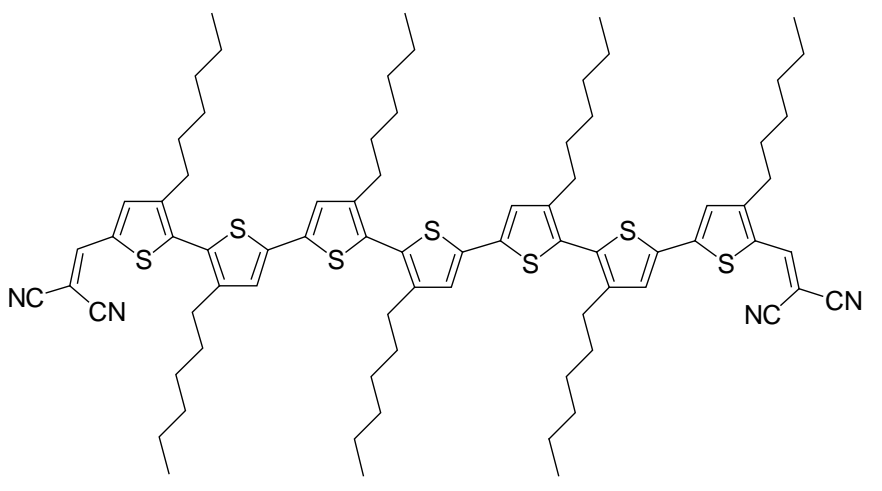

S25

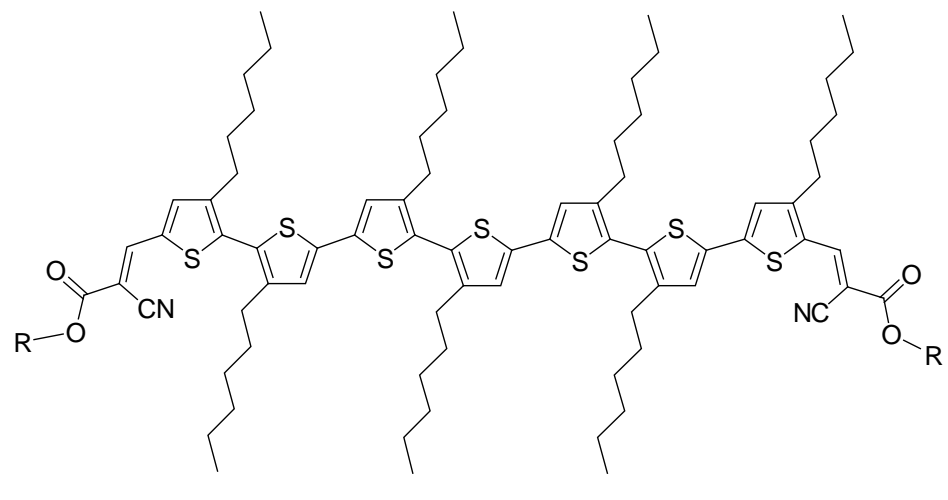

S26

$\mathrm{R}=$ ethyl (DCAE7T), octyl (DCAE7T), 2-ethylhexyl (DCAE7T)

\section{Chart 8}

非常好的结晶性, 其中 S25 的摩尔吸光系数高达 110000 $\mathrm{L} \cdot \mathrm{mol}^{-1} \cdot \mathrm{cm}^{-1}$, 光学带隙仅为 $1.68 \mathrm{eV}$. 以 $\mathrm{S} 25$ 为给体, $\mathrm{PC}_{61} \mathrm{BM}$ 为受体制备的体异质结太阳能电池, 获得了 $3.7 \%$ 的光电转换效率 ${ }^{[42]}$. 最近该小组通过对 S25 在分子 结构上的优化, 构建了新的 D-A 型小分子 S26 (Chart

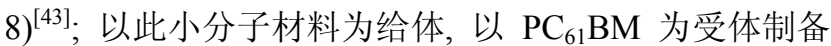
的体异质结太阳能电池, 其最高光电转换效率为 $5.08 \%$.

2.3 基于 2-吡喃-4-亚基丙二氭(PM)构建的给体-受体 有机小分子

在构建基于 PM 单元的可溶液加工有机小分子方 
面, 中国科学院化学研究所的李永舫教授研究组和吉林 大学的田文晶教授研究组分别做了大量而又系统的研 究工作, 取得了很多有意义的研究成果.
2007 年，李永舫小组基于三苯胺、苯和 PM 基团构 建了可溶液加工的有机小分子 S27 (Chart 9) ${ }^{[44]}$. 小分子<smiles>N#CC(C#N)=C1C=C(/C=C/c2ccc(/C=C/c3ccc(N(c4ccccc4)c4ccccc4)cc3)cc2)OC(/C=C/c2ccc(/C=C/c3ccc(N(c4ccccc4)c4ccccc4)cc3)cc2)=C1</smiles><smiles>C=Cc1ccc(N(CC)c2ccc(/C=C/c3ccc(/C=C/C4=CC(=C(C#N)C#N)C=C(/C=C/c5ccc(/C=C/c6ccc(N(c7ccccc7)c7ccccc7)cc6)cc5)O4)cc3)cc2)cc1</smiles>

S28<smiles>N#CC(C#N)=C1C=C(/C=C/c2ccc(/C=C/c3ccc(Nc4ccc(/C=C/c5ccc(/C=C/c6ccc(N(c7ccccc7)c7ccccc7)cc6)cc5)cc4)cc3)cc2)OC(/C=C/c2ccc(/C=C/c3ccc(N(c4ccccc4)c4ccccc4)cc3)cc2)=C1</smiles><smiles>N#CC(C#N)=C1C=C(/C=C/c2ccc(/C=C/c3ccc(N(c4ccccc4)c4ccccc4)cc3)s2)OC(/C=C/c2ccc(/C=C/c3ccc(N(c4ccccc4)c4ccccc4)cc3)s2)=C1</smiles><smiles>CCCCCCc1cc(/C=C/C2=CC(=C(C#N)C#N)C=C(/C=C/c3cc([SH2+])c(/C=C/c4ccc(N(c5ccccc5)c5ccccc5)cc4)s3)O2)sc1/C=C/c1ccc(N(c2ccccc2)c2ccccc2)cc1</smiles>

S31

\section{Chart 9}


S27 展现了相对较宽的吸收光谱, 以小分子为给体, $\mathrm{PC}_{61} \mathrm{BM}$ 为受体制备的体异质结太阳能电池, $V_{\mathrm{oc}}$ 高达 $0.90 \mathrm{~V}$, 光电转换效率为 $0.79 \% .2009$ 年, 该小组 ${ }^{[45]}$ 在小 分子 S27 的基础上, 设计并合成了分子量更大, 共轭长 度更长, 具有空间多维性的 D-A 型小分子 S28 和 S29 (Chart 9). 由于分子共轭长度的增加, 吸收光谱发生了 明显的红移, 光学带隙由原来的 $1.88 \mathrm{eV}$ 降为 $1.65 \mathrm{eV}$. 以 $\mathrm{S} 28$ 为给体, $\mathrm{PC}_{61} \mathrm{BM}$ 为受体制备的体异质结太阳能 电池, 其光电转换效率可达 $0.73 \% .2011$ 年, 该小组 ${ }^{[46]}$ 基于三苯胺、噻吩和 PM 基团构建了新的可溶液加工的 D-A 型有机小分子 S30 和 S31 (Chart 9); 研究发现, 通过 将小分子 S27 内的桥联基团苯取代为噻吩, 分子在固体 薄膜状态下的吸收光谱发生了大约 $50 \mathrm{~nm}$ 的红移. 分别 以 S30 和 S31 为给体, $\mathrm{PC}_{71} \mathrm{BM}$ 为受体制备的体异质结太 阳能电池, 其光电转换效率依次为 $2.06 \%$ 和 $2.10 \%$.

2009 年, 田文晶小组 ${ }^{[47]}$ 以可溶液加工的 D-A 型小 分子 S32 为给体(Chart 10), 以 $\mathrm{PC}_{61} \mathrm{BM}$ 为受体制备了体 异质结太阳能电池, 器件的 $V_{\mathrm{oc}}$ 高达 $1.0 \mathrm{~V}$, 光电转换效 率为 $1.50 \%$. 该研究表明, 具有简单 D-A 型结构的有机 共轭小分子同样具有较宽的吸收光谱、较高的载流子迁 移率以及较高的器件光电转换效率. 次年, 该小组 ${ }^{[34]}$ 以齐聚噻吩为给电子基团, PM 为吸电子基团构建了一 系列含有不同噻吩单元的有机小分子 S33 S35 (Chart 10). 研究发现, 这些小分子均具有较好的结晶性, 随着 分子中噻吩单元数目的增加, 分子的热稳定性逐渐增 强. 同时, 分子共轭长度的增加和共平面性的提高增强 了分子间的 $\pi-\pi$ 堆积效应, 进而大大拓宽分子固体薄膜 的吸收光谱, 提高了材料的迁移率. 光伏器件研究发现, 分子中噻吩单元数目的调节, 有效改善了器件的光伏性 能. 以 S34 为给体, $\mathrm{PC}_{61} \mathrm{BM}$ 为受体制备的体异质结太阳 能电池, 实现了 $1.13 \%$ 的光电转换效率. 2011 年, 该小 组 ${ }^{[34 b]}$ 以三苯胺为给电子基团, PM 为吸电子基团, 吩噻 溙, 三苯胺和噻吩分别为桥联基团构建了一系列可溶液 加工的有机小分子 $\mathbf{S 3 6} \sim \mathbf{S 3 8}$ (Chart 10). 随着分子中桥 联基团的改变, 分子的 HOMO 能级逐渐降低, 空气稳定 性得到增强, 迁移率得到明显的改善. 光伏器件研究发 现, 随着分子中桥联基团的有效调节, 器件的 $V_{\mathrm{oc}}$ 由 0.8 $\mathrm{V}$ 提高到 $1.0 \mathrm{~V}$, 短路电流 $\left(J_{\mathrm{sc}}\right)$ 由 $2.33 \mathrm{~mA} \cdot \mathrm{cm}^{-2}$ 提高到 $3.85 \mathrm{~mA} \cdot \mathrm{cm}^{-2}$, 光电转换效率由 $0.65 \%$ 提高到 $1.31 \%$. 随后, 该小组 ${ }^{[48]}$ 基于给电子基团三苯胺, 噻吩和吸电子 基团 PM 构建了一系列无定形小分子 $\mathbf{S 3 9} \sim \mathbf{S 4 1}$ (Chart 10). 随着分子外围噻吩单元数目和长度的变化, 分子 的光密度得到了提高, 活性层的表面形貌得到了较大的 改善. 分别以 $\mathbf{S 3 9}$ 和 $\mathrm{S40}$ 为给体, $\mathrm{PC}_{71} \mathrm{BM}$ 为受体制备了 体异质结太阳能电池, 其中基于 $\mathbf{S 4 0}$ 和 $\mathrm{PC}_{71} \mathrm{BM}$ 器件达
到了 $2.47 \%$ 的光电转换效率，这也是目前基于 PM 基团 有机小分子体异质结太阳能电池的最高光电转换效率.

\section{3 基于吡咯并吡咯二酮构建的给体-受体有机 小分子}

近几年, Nguyen 等 ${ }^{[49 \sim 51,13]}$ 报道了一系列包含吡咯 并吡咯二酮(DPP)的有机小分子给体材料, 并将其应用 于有机太阳能电池. 这些小分子以强吸电子基团 DPP 为核, 在其 2,5 位修饰以噻吩单元或噻吩衍生物, 在其 内酰胺环的含 $\mathrm{N}$ 位置修饰以不同的烷基链, 以调节分子 的 $\pi-\pi$ 堆积效应、热稳定性、结晶性、能级和分子的自 组装性能. 这些材料经过热退火后，由于分子结构和基 团自身的特点(噻吩和 DPP 都具有较强的共平面性和结 晶性), 形成了高度有序的纳米结构.

2008 年, Nguyen 小组 ${ }^{[49]}$ 基于 DPP 基团和不同数目 的噻吩单元构建了一系列的有机小分子 S42 S44 (Chart 11). 随着分子中噻吩单元的增加其结晶温度逐 渐升高，热稳定性逐渐增强. 同时，这些小分子具有非 常宽的吸收光谱, 随着分子中噻吩单元的增加其吸收光 谱逐渐红移. 原子力显微镜研究发现, 这些小分子的薄 膜出现了很多类似纤维状的结构, 证明分子在成膜的过 程中出现了自组装的现象. 在随后的工作中, 该小组基 于 DPP 单元和三联噻吩构建了可溶液加工的有机小分 子 S45 (Chart 11) ${ }^{[50]}$, 该小分子展现了非常宽的吸收光 谱 $(300 \sim 850 \mathrm{~nm})$. 以 $\mathrm{S} 45$ 为给体, $\mathrm{PC}_{61} \mathrm{BM}$ 为受体制备的 体异质结太阳能电池, 其 $V_{\mathrm{oc}}$ 为 $0.67 \mathrm{~V}, J_{\mathrm{sc}}$ 为 $8.42 \mathrm{~mA}$ $\mathrm{cm}^{-2}, \mathrm{FF}$ 为 0.45 , 光电转换效率高达 $2.33 \%$. 器件的活 性层具有较低的粗粘度并出现了很多纤维状的结构, 表 明小分子与受体之间具有较好的相容性, 分子在成膜的 过程中出现了自组装的现象. 2009 年, 该小组 ${ }^{[51]}$ 通过调 节小分子 S45 上的烷基链类型(烷基代替酯基)，设计并 合成了 D-A 型小分子 S46. 以(5-正己基-[2,2,5,2]-三联噻 吩-5-基)-吡咯并 [3,4-c]吡咯-1,4-二酮(SMDPPEH)为给 体, $\mathrm{PC}_{71} \mathrm{BM}$ 为受体制备了体异质结太阳能电池, 得到了 $V_{\mathrm{oc}}$ 为 $0.75 \mathrm{~V}, J_{\mathrm{sc}}$ 为 $9.2 \mathrm{~mA} \cdot \mathrm{cm}^{-2}, \mathrm{FF}$ 为 0.44 , 光电转换效 率高达 $3.0 \%$ 的光伏器件. 研究发现, 烷基链的改变提高 了器件的 $V_{\mathrm{oc}}$, 而受体 $\mathrm{PC}_{71} \mathrm{BM}$ 的使用则提高了器件的 $J_{\mathrm{sc}}$. 为了进一步提高器件的 $V_{\mathrm{oc}}$ 和光电转换效率, 该小 组 ${ }^{[13]}$ 以苯并呋喃代替给电子基团中的联噻吩, 构建了 $\mathrm{D}-\mathrm{A}$ 型小分子 $\mathbf{S 4 7}$. 以 $\mathbf{S 4 7}$ 为给体, $\mathrm{PC}_{71} \mathrm{BM}$ 为受体制备 的体异质结太阳能电池, $V_{\mathrm{oc}}$ 高达 $0.92 \mathrm{~V}, J_{\mathrm{sc}}$ 为 10.0 $\mathrm{mA} \cdot \mathrm{cm}^{-2}, \mathrm{FF}$ 为 0.48 , 光电转换效率高达 $4.4 \%$, 这也是 迄今为止基于 DPP 单元可溶液加工的 D-A 型小分子的 最高光电转换效率. 


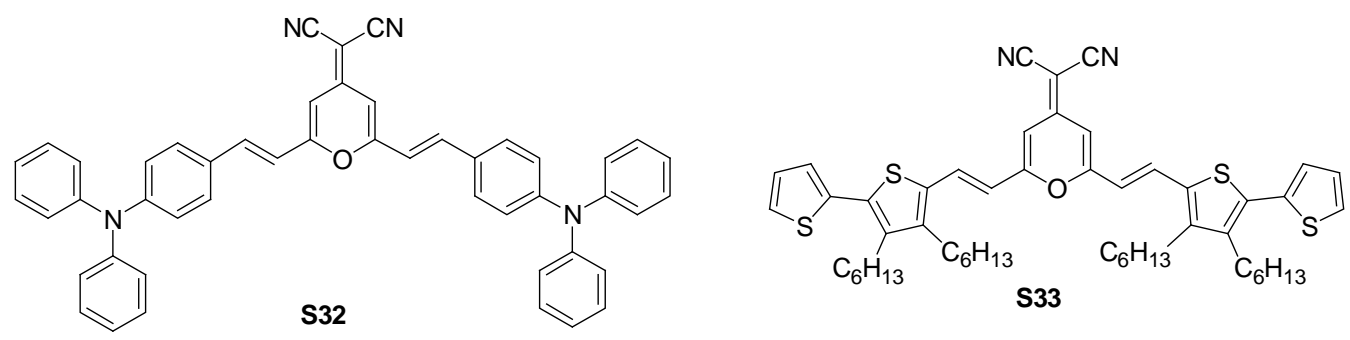

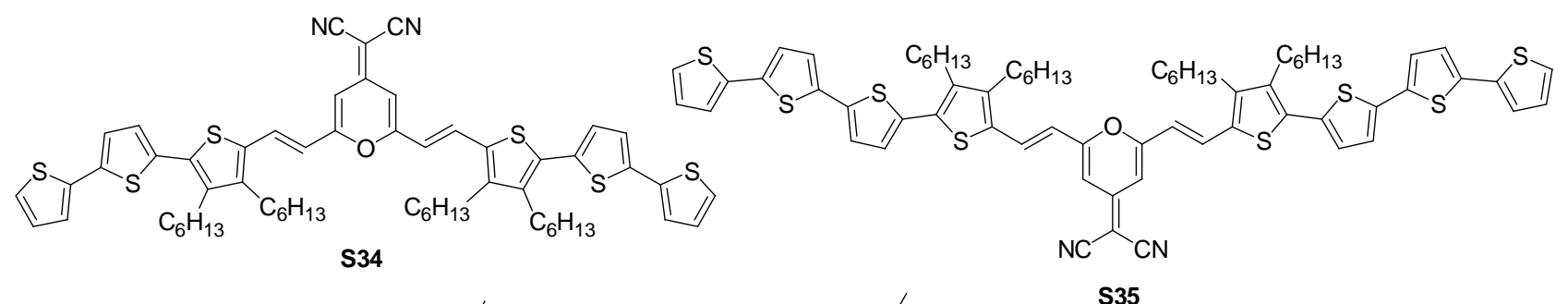

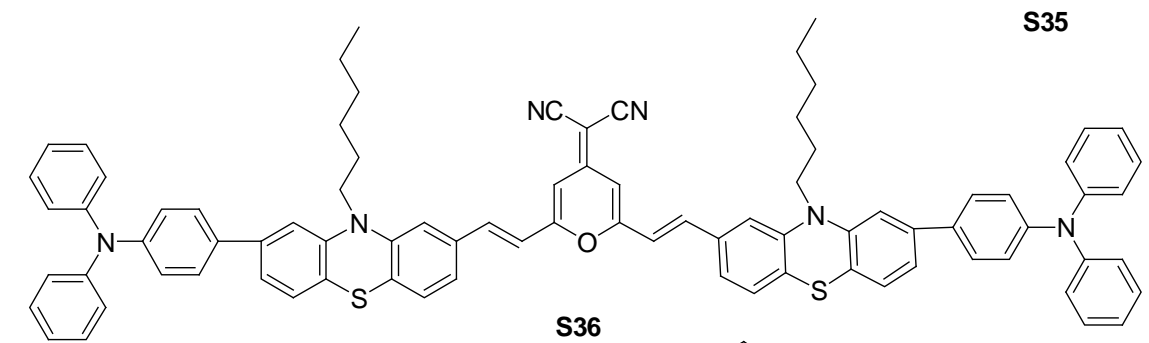<smiles>N#CC(C#N)=C1C=C(/C=C/c2ccc(N(c3ccccc3)c3ccc(-c4ccc(N(c5ccccc5)c5ccccc5)cc4)cc3)cc2)O/C(=C/C=C/c2ccc(N(c3ccccc3)c3ccc(-c4ccc(N(c5ccccc5)c5ccccc5)cc4)cc3)cc2)C1</smiles>

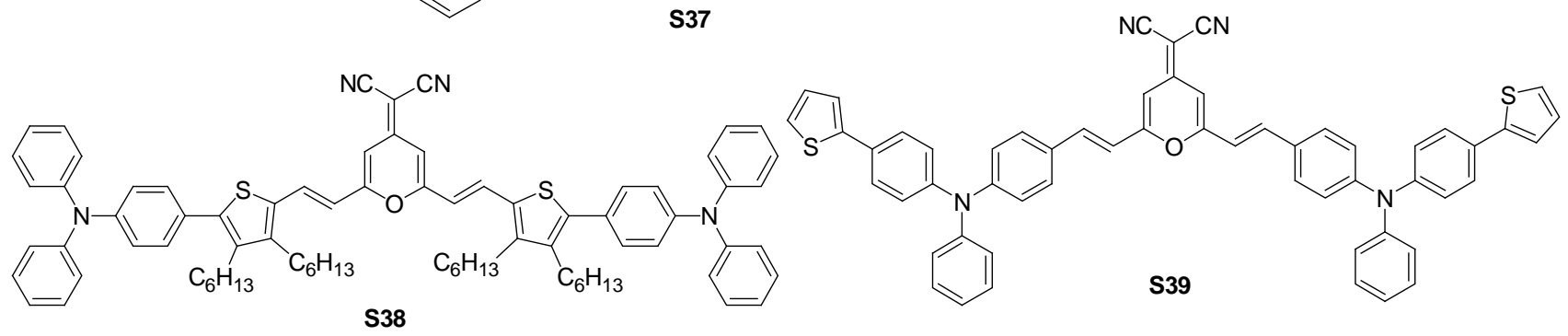

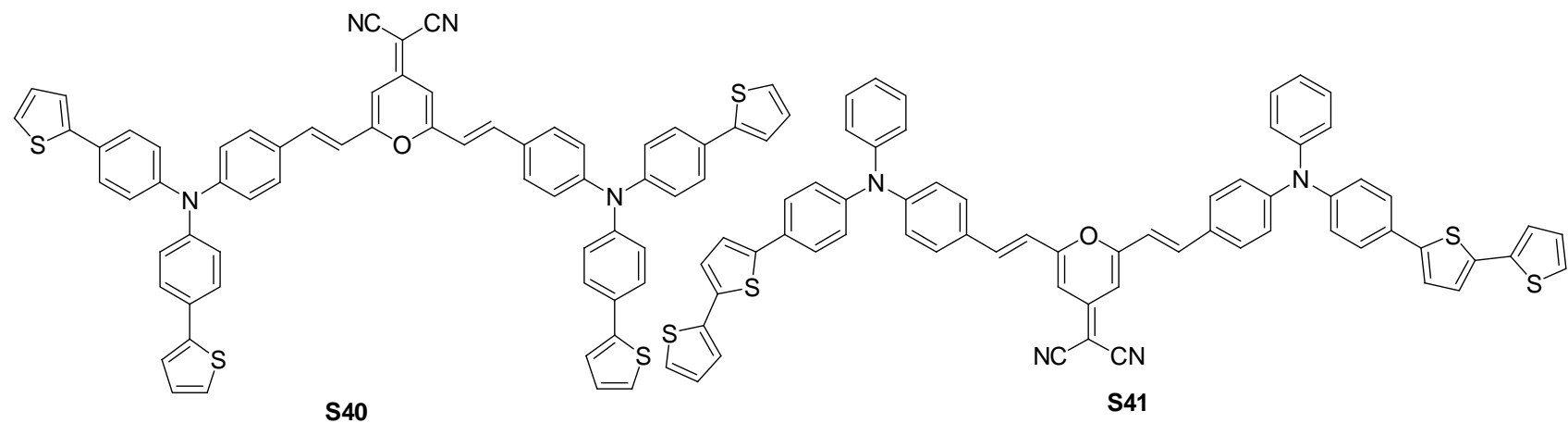

Chart 10 
<smiles></smiles>

S42<smiles>[R]N1C(=O)C2=C(c3ccc(-c4cccs4)s3)N([R])C(=O)C2=C1c1ccc(-c2cccs2)s1</smiles>

$\mathrm{S} 43$

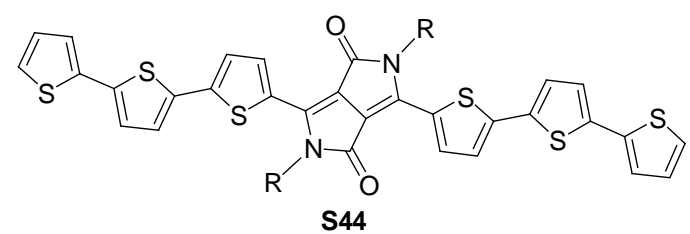

S44

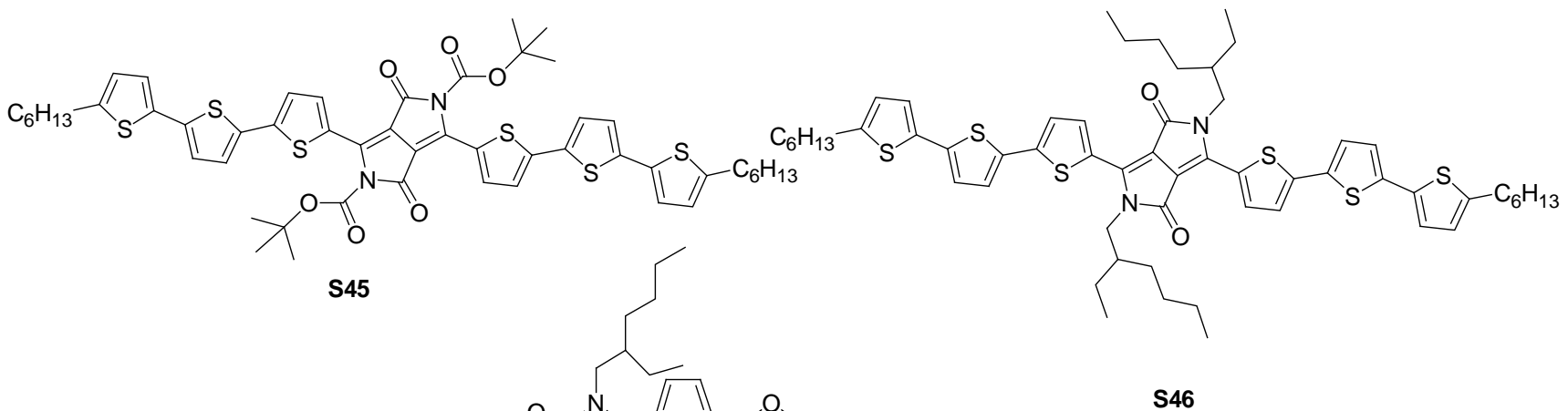

S47

\section{Chart 11}

2011 年, 美国华盛顿大学的 Luscombe 研究小组 ${ }^{[2]}$ 以硒吩为给电子基团, DPP 为吸电子基团首次构建了基 于硒吩的有机小分子 S48 和 S49, 并将其应用于体异质 结太阳能电池(Chart 12). 其中, 以 $\mathbf{S 4 8}$ 为给体, $\mathrm{PC}_{61} \mathrm{BM}$ 为受体制备的体异质结太阳能电池, 实现了 $1.53 \%$ 的光 电转换效率, 显示了硒吩衍生物在体异质结太阳能电池 方面有着较好的应用前景. 同年, 美国西北大学的 Facchetti 研究组 ${ }^{[53]}$ 基于荟并二噻吩(NDT)、噻吩和 DPP 单元构建了新型可溶液加工的有机小分子 S50 (Chart 12). 由于小分子自身的高共平面性，其迁移率高达 7.18 $\times 10^{-3} \mathrm{~cm}^{2} \cdot \mathrm{V}^{-1} \cdot \mathrm{s}^{-1}$, 这也是目前可溶液加工 D-A 型小 分子的最高迁移率. 以 $\mathrm{S} 50$ 为给体, $\mathrm{PC}_{61} \mathrm{BM}$ 为受体制备 的体异质结太阳能电池, 实现了 $4.06 \%$ 的高光电转换效 率.

\section{4 基于份菁、硼络合二吡咯和方酸构建的给体- 受体有机小分子}

在近几年的研究工作中, 染料基团份菁、硼络合二 吡咯和方酸被广泛的应用于构建 D-A 型的有机共轭小 分子, 获得了较高的摩尔吸光系数、较宽的吸收光谱和
较好的光电性能. 2008 年，德国的 Meerholz 研究组 ${ }^{[54]}$ 基 于份菁染料合成了一系列可溶液加工的 D-A 型小分子 (Chart 13). 这些小分子具有较高的摩尔吸光系数, 其中 小分子 S57 的摩尔吸光系数高达 $1.4 \times 10^{5}{\mathrm{~L} \cdot \mathrm{mol}^{-1}}^{-}$ $\mathrm{cm}^{-1}$. 随着分子中吸电子基团能力的增强，分子的 LUMO 能级逐渐降低, 器件的 $V_{\mathrm{oc}}$ 也得到了提升. 以小 分子 $\mathrm{S} 57$ 为给体, $\mathrm{PC}_{61} \mathrm{BM}$ 为受体制备的体异质结太阳 能电池, 实现了 $1.74 \%$ 的较高光电转换效率.

2009 年, 法国的 Roncali 研究组 ${ }^{[55]}$ 基于染料硼络合 二吡咯(BODIPY)合成了可溶液加工的有机共轭小分子 S58 和 S59 (Chart 14), 其中以 S58 为给体, $\mathrm{PC}_{61} \mathrm{BM}$ 为受 体制备的体异质结太阳能电池, 光电转换效率达到了 $1.34 \%$. 在随后的研究工作中, 该小组 ${ }^{[56]}$ 通过在 S58 中 引入齐聚噻吩，构建了新的嗍络合二吡咯衍生物 $\mathbf{S 6 0}$ (Chart 14), 分子的吸收光谱得到了拓宽, 迁移率得到了 明显的提高, 器件的光电转换效率也因此由原来的 $1.34 \%$ 提高到 $2.20 \%$.

2008 年, Marks 研究组 ${ }^{[57]}$ 基于方酸(SQ)构建了有机 D-A 型小分子 S61 (Chart 15), 小分子 $\mathbf{S 6 1}$ 的摩尔吸光系 数高达 $2 \times 10^{5} \mathrm{~L} \cdot \mathrm{mol}^{-1} \cdot \mathrm{cm}^{-1}$. 以 $\mathbf{S 6 1}$ 为给体, $\mathrm{PC}_{61} \mathrm{BM}$ 


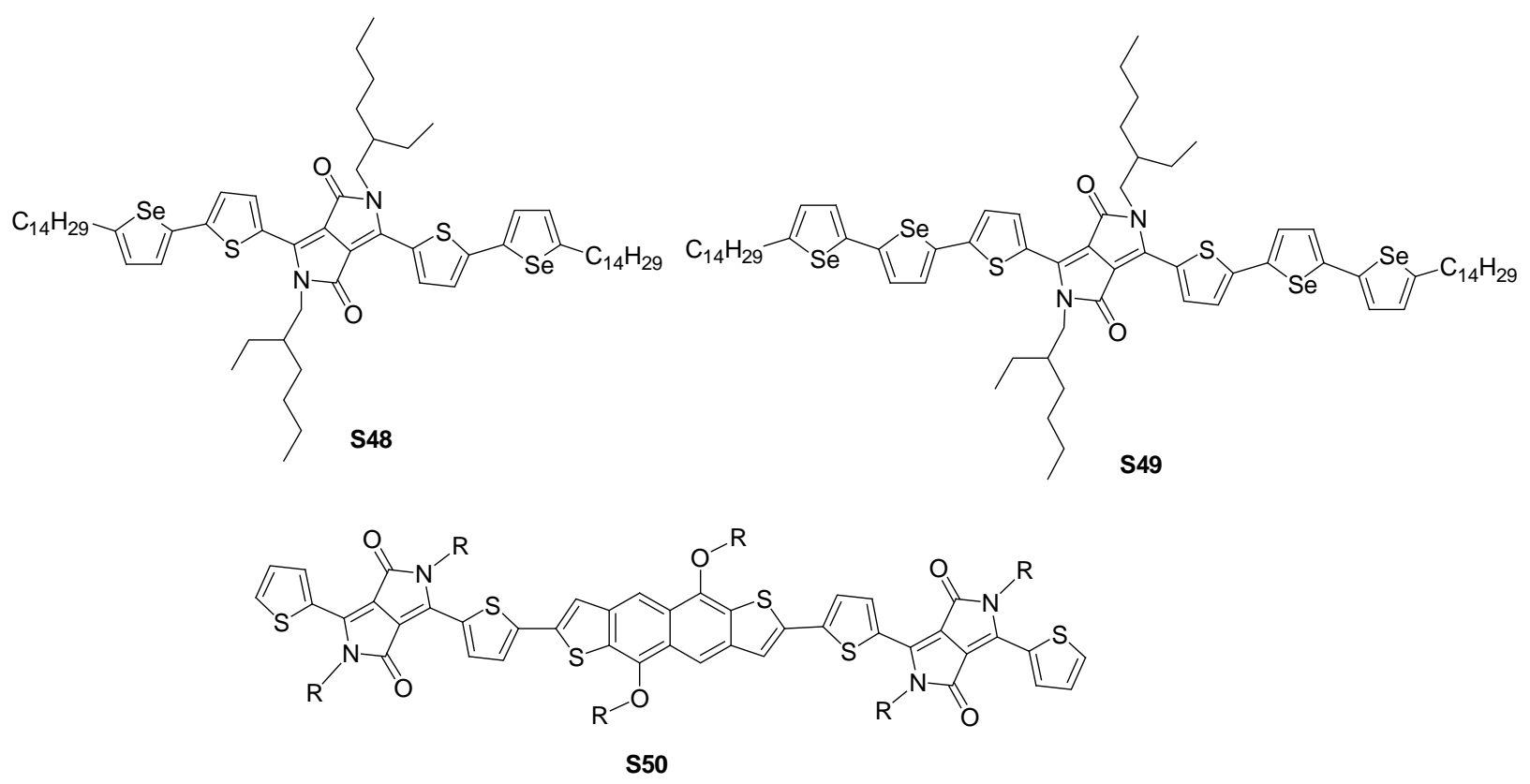

Chart 12<smiles>CC(C)(C)CN(Cc1ccccc1)c1ccc(/C=C2\C(=O)ON=C2c2ccccc2)s1</smiles>

S51<smiles>CCCCC(CC)CN1C(=O)C(=CC=C2N(Cc3ccccc3)c3ccccc3C2(C)C)C(C)C(C#N)C1=O</smiles>

S55

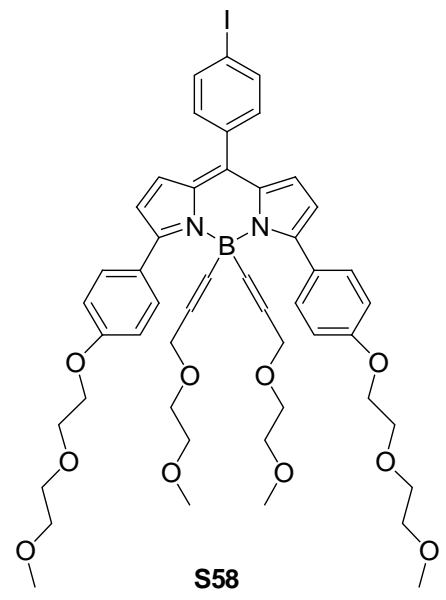<smiles></smiles>

S52<smiles>CCCCCN1C(=CC=C2C(=O)c3ccccc3C2=C(C#N)C#N)C(C)(C)c2ccccc21</smiles>

Chart 13

Chart 14<smiles>CCCCC(CC)CN1C(=O)C(=Cc2ccc(N(Cc3ccccc3)C(=O)c3ccccc3)s2)C(C)C(C#N)C1=O</smiles><smiles></smiles>
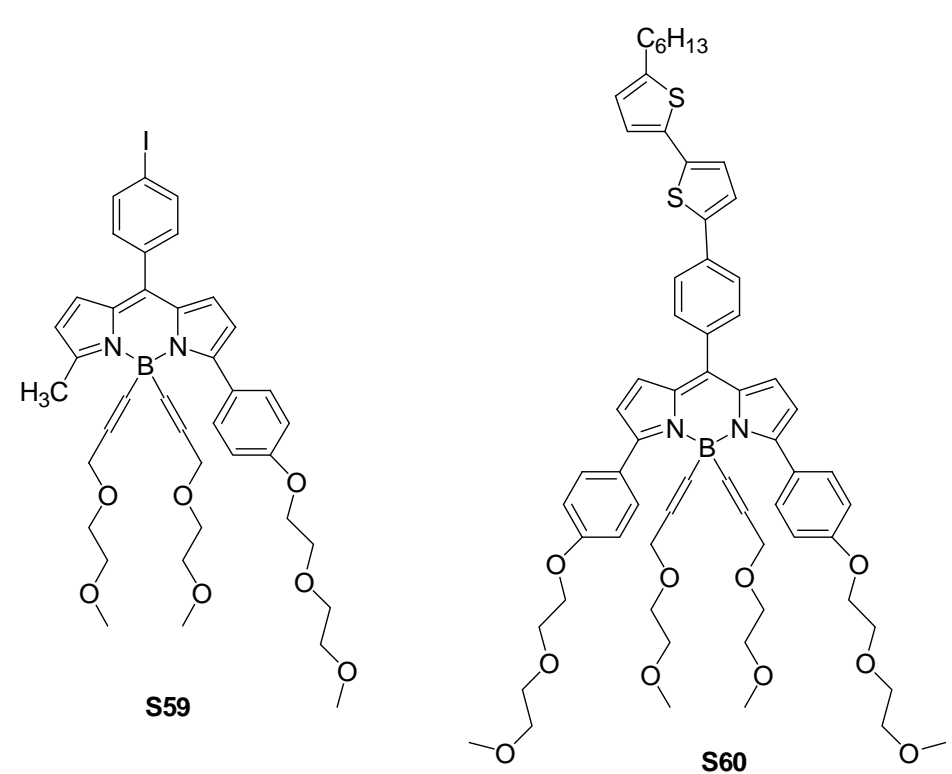

$\mathrm{S} 60$ 


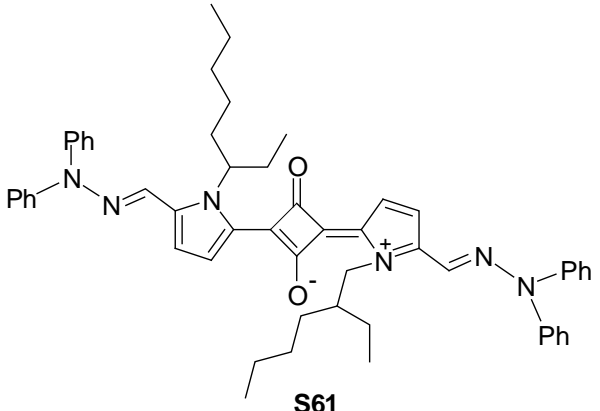

S61

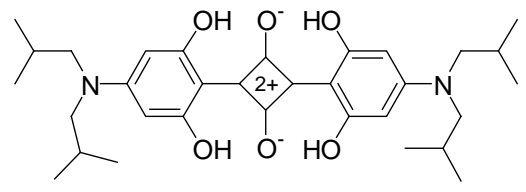

S63

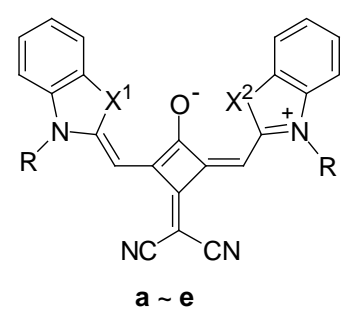

a: $X^{1}=X^{2}=\mathrm{CMe}_{2}, \mathrm{R}=i-\mathrm{Pr}$

b: $\mathrm{X}^{1}=\mathrm{X}^{2}=\mathrm{CMe}_{2}, \mathrm{R}=n-\mathrm{Bu}$

c: $X^{1}=X^{2}=O, R=n-B u$

d: $X^{1}=X^{2}=S, R=n-B u$

e: $X^{1}=S, X^{2}=\mathrm{CMe}_{2}, \mathrm{R}=n-\mathrm{Bu}$

S62

\section{Chart 15}

为受体制备的体异质结太阳能电池, 实现了 $1.24 \%$ 的光 电转换效率. 2009 年, Würthner 研究组基于 SQ 设计并合 成了一系列 D-A 型小分子 $\mathbf{S 6 2}$ (Chart 15), 其中以小分 子 $\mathbf{S 6 2 d}$ 为给体, $\mathrm{PC}_{61} \mathrm{BM}$ 为受体制备的体异质结太阳能 电池, $J_{\mathrm{sc}}$ 高达 $12.6 \mathrm{~mA} \cdot \mathrm{cm}^{-2}$, FF 为 0.49 , 由于器件的 $V_{\mathrm{oc}}$ 只有 0.31 , 最终的光电转换效率仅为 $1.79 \% .2010$ 年, 美 国密歇根大学的 Forrest 小组 ${ }^{[58,15]}$ 以方酸衍生物 S63 (Chart 15)为给体, $\mathrm{PC}_{71} \mathrm{BM}$ 为受体制备了体异质结太阳 能电池, 经过器件优化, 实现了 $5.5 \%$ 的光电转换效率, 这也是目前有机小分子体异质结太阳能电池的最高光 电转换效率.

\section{5 基于其它吸电子基团构建的给体-受体有机 小分子}

2005 年, 刘云圻研究组 ${ }^{[59]}$ 分别以三苯胺、吩噻嗪和 咔唑为给电子基团, 2-(5,5-二甲基环已基-2-乙烯基)丙二 氧(CEM)为吸电子基团构建了一系列可溶液加工的 D-A 型小分子 $\mathbf{S 6 4} \sim \mathbf{S 6 6}$ (Chart 16). 其中基于 BDHT 制备的 单层有机太阳能电池, 实现了 $0.03 \%$ 的光电转换效率. 2007 年, 田文晶小组 ${ }^{[60]}$ 以小分子 $\mathbf{S 6 6}$ 为给体, $\mathrm{PC}_{61} \mathrm{BM}$ 为受体制备的体异质结太阳能电池, 实现了 $0.51 \%$ 的光 电转换效率.

2008 年, Demadrille 小组 ${ }^{[61]}$ 以齐聚噻吩或并噻吩为 给电子基团, 芴酮为吸电子基团构建了一系列可溶液加 工的 D-A 型小分子 $\mathbf{S 6 7} \sim \mathbf{S 7 0}$ (Chart 17). 以 $\mathbf{S 7 0}$ 为给体, $\mathrm{PC}_{61} \mathrm{BM}$ 为受体制备的体异质结太阳能电池, 实现了 $1.2 \%$ 的较高光电转换效率. 研究发现, 分子中噻吩单元 结构或数目的变化有效地改善了器件的光伏性能.<smiles>CC1(C)CC(/C=C/c2ccc(N(c3ccccc3)c3ccc(/C=C/C4=CC(=C(C#N)C#N)CC(C)(C)C4)cc3)cc2)=CC(=C(C#N)C#N)C1</smiles><smiles>CCCn1c2ccc(/C=C/C3=CC(=C(C#N)C#N)CC(C)(C)C3)cc2c2cc(/C=C/C3=CC(=C(C#N)C#N)CC(C)(C)C3)ccc21</smiles><smiles>CCCN1c2ccc(/C=C/C3=CC(=C(C#N)C#N)CC(C)(C)C3)cc2Sc2cc(/C=C/C3=CC(=C(C#N)C#N)CC(C)(C)C3)ccc21</smiles>

Chart 16

2009 年, 田文晶小组 ${ }^{[62]}$ 以三苯胺为给体, 二苯亚砜 (SDB) 为受体构建了一系列的树状大分子 $\mathbf{S 7 1} \sim \mathrm{S73}$ (Chart 18). 随着分子中给体部分三苯胺单元的增加, 分 


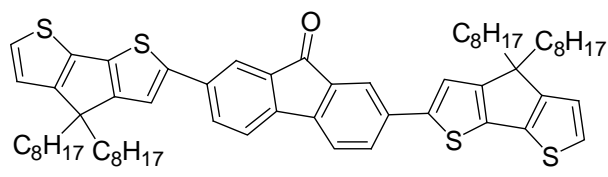

S67

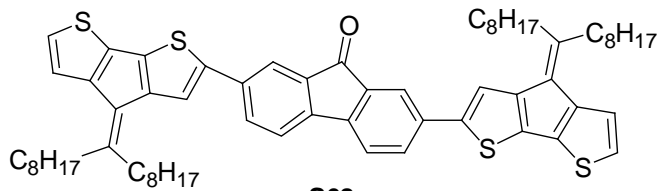

S68

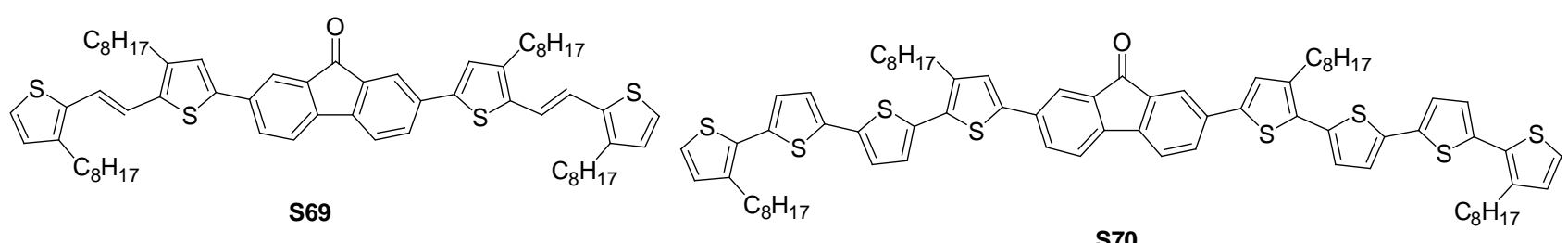

Chart 17

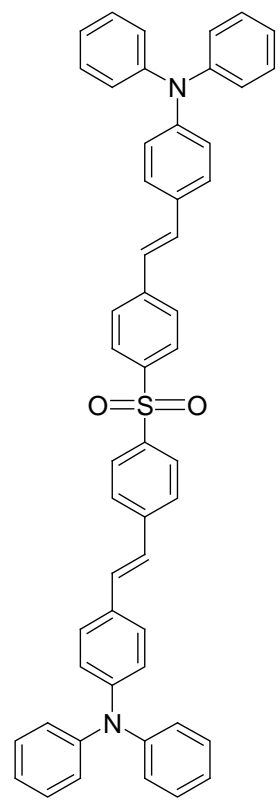

S71
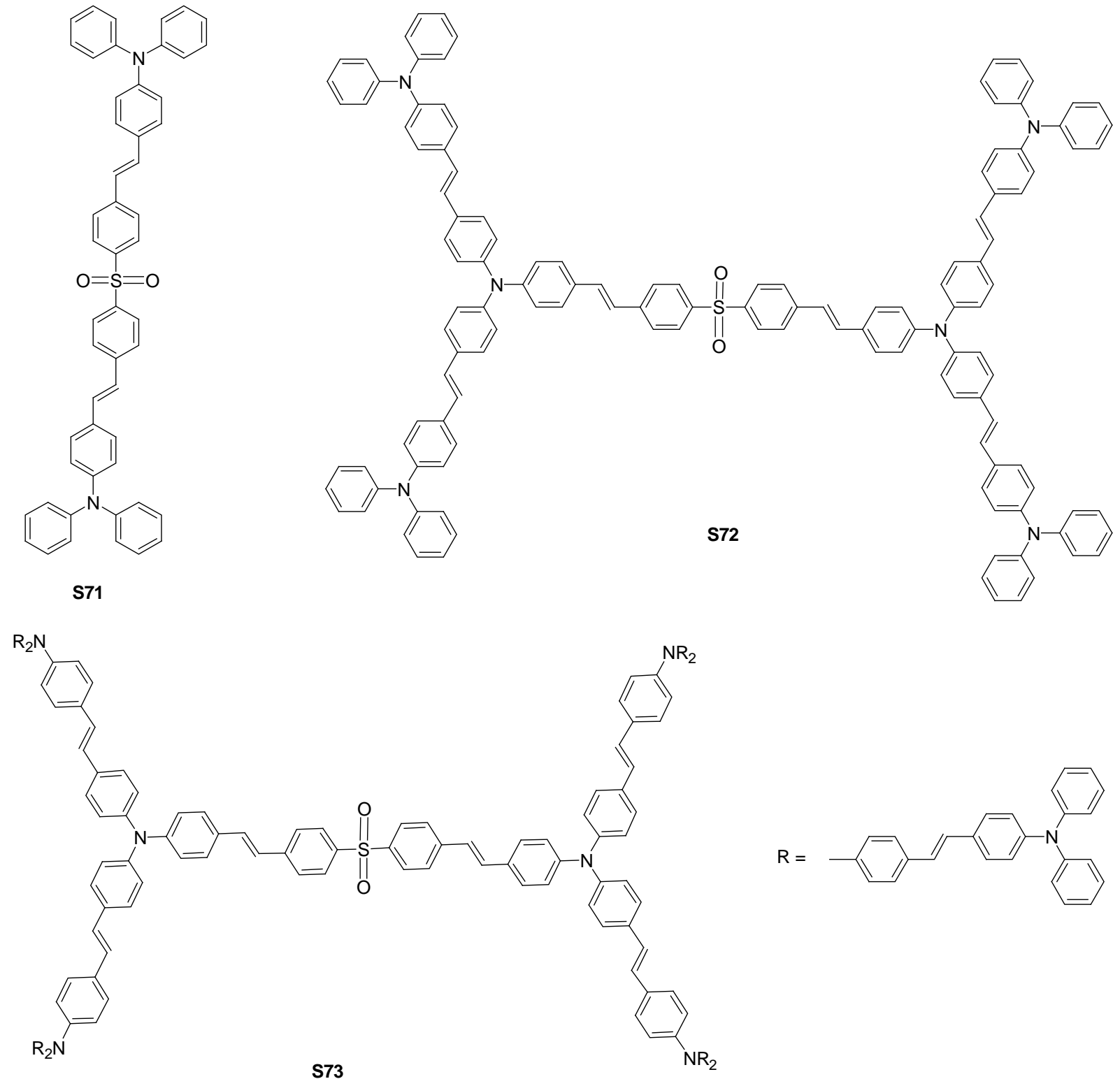

Chart 18

子的空间位阻越来越大, 大大降低了分子间的堆积效 应. 同时, 由于分子结构的改变, 使得分子与 $\mathrm{PC}_{61} \mathrm{BM}$
的相容性越来越差, 导致了光伏器件性能的降低.

2010 年, 佛罗里达大学的 Reynolds 小组 ${ }^{[63]}$ 以齐聚 
噻吩为给电子基团, 异靛为吸电子基团构建了可溶液加 工的 D-A 型小分子 S74 和 S75 (Chart 19). 其中以小分子 S74 为给体, $\mathrm{PC}_{61} \mathrm{BM}$ 为受体制备的体异质结太阳能电 池, 实现了 $1.76 \%$ 的光电转换效率. 同年, 加利福尼亚 大学的马柘武小组 ${ }^{[64]}$ 首次基于喹呋啶酮构建了可溶液 加工的 D-A 型小分子 S76 (Chart 19)并将其应用于体异 质结太阳能电池, 实现了 $2.22 \%$ 的光电转换效率. 在最 近的研究工作中, Bazan 等 ${ }^{[20]}$ 以噻吩和二噻吩并噻咯为 给电子基团, $[1,2,5]$ 噻二唑 $[3,4-c]$ 氮苯 $(\mathrm{PT})$ 为吸电子基 才, 构建了新的 D-A 型小分子 DTS $\left(\mathrm{PTTh}_{2}\right)_{2}(\mathrm{S77})$, 以小 分子为给体, $\mathrm{PC}_{70} \mathrm{BM}$ 为受体制备的体异质结太阳能电 池, 经过添加不同比例的 1,8-二碘辛烷的处理后, 器件 的光电转换效率高达 $6.7 \%$, 这也是迄今为止有机小分 子太阳能电池的最高光电转换效率.

\section{6 小结与展望}

通过以上的综述可以看到, 在最近几年的研究工作 中, 科研工作者们对 D-A 型有机小分子在可溶液加工有 机体异质结太阳能电池中的应用倾注了大量的心血. 也 正是人们这种孜孜不倦的追求和刻苦的努力, 有机小分 子体异质结太阳能电池的光电转换效率得到了极大地 提升, 距离有机太阳电池工业化的脚步也越来越近. 本 文通过上面的综述，对设计并合成高效率的 D-A 型小分 子给体材料提出以下几点建议(图 1):(1)材料应该具备 足够大的溶解度以保证其可以进行溶液加工. 通过以上 对各种材料的综述我们不难发现, 人们在设计并合成具
有较高溶解度的有机共轭分子时一般采取以下几个方 面的措施：(i)在分子中引入一定长度的烷基链或烷氧基 链. 一般来说, 烷基链(烷氧基链)越长, 增溶效果越好. 但是，分子中过长烷基链(烷氧基链)的存在，可能会抑 制分子间的 $\pi-\pi$ 堆积，从而可能降低分子固体薄膜状态 下对太阳光子的吸收. 因此, 要选择长度适当的烷基链 (烷氧基链)增强分子的溶解性. (ii)在分子中引入具有空 间多维性的三苯胺基团. 三苯胺由于具有三维立体结 构, 在被引入到分子当中后，在一定程度上破坏了分子 的共轭性，降低了分子的刚性，从而增强分子的溶解性. (iii)在设计分子的时候, 多采用单键连接各基团, 尽可 能避免共轭双键的引入. 因为共轭双键的存在会增强分 子的刚性，从而降低分子的溶解性. (2)材料应该具备较 宽的吸收光谱以满足活性层对太阳光子的吸收. 通过前 面的综述我们可以看到，人们在拓宽分子的吸收光谱方 面做了大量的工作，也取得了成功，使得有机小分子的 吸收光谱可以拓宽到 $900 \mathrm{~nm}^{[49,50,57]}$. 概括来说, 在拓宽 分子的吸收光谱方面，人们一般采取以下方式: (i)构建 D-A 型的有机共轭分子，同时注意调控给电子基团的给 电子能力和吸电子基团的吸电子能力 ${ }^{[10]}$, 因为在 $\mathrm{D}-\mathrm{A}$ 型分子中存在分子内电荷转移现象. 首先, 这一现象的 存在可以大大拓宽分子的吸收光谱. 其次, 通过增强分 子中给电子基团的给电子能力或吸电子基团的吸电子 能力都可以增强分子内电荷转移的强度, 从而拓宽分子

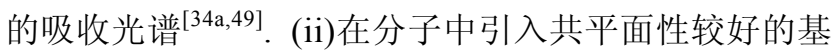<smiles>[R]N1C/C(=C2/C(=O)N([R])c3cc(-c4ccc(-c5ccc(CCCCC)s5)s4)ccc32)c2ccc(-c3ccc(-c4ccc(CCCCC)s4)s3)cc21</smiles>

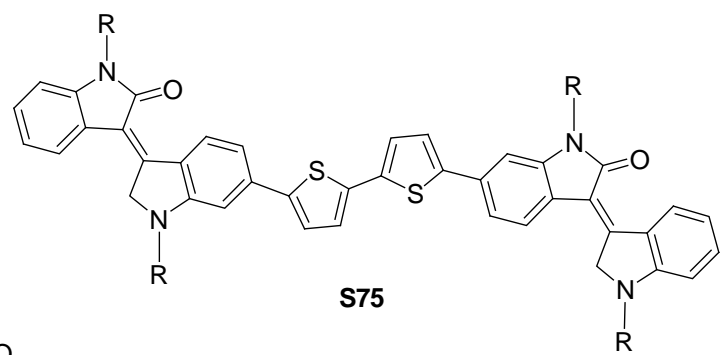

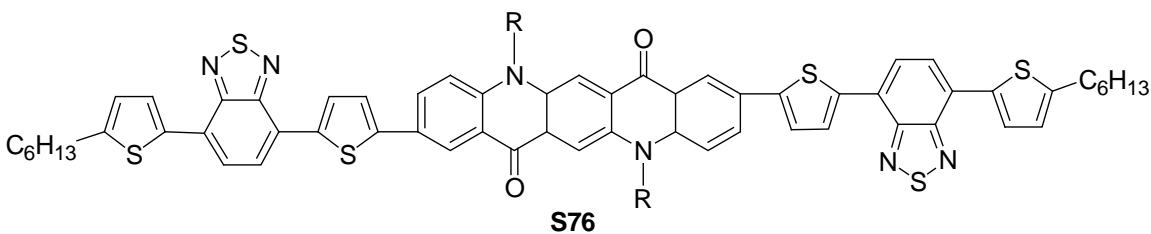<smiles></smiles>

S77

\section{Chart 19}


团, 增强分子间的 $\pi-\pi$ 堆积效应. 例如分子中齐聚噻吩 和稠环基团的引 ${ }^{[20,50]}$, 可以有效地增强分子的共平面 性, 从而使得分子在固体薄膜中存在较好的 $\pi-\pi$ 堆积效 应，进而拓宽分子的吸收光谱. (3)在设计材料时，应考 虑材料的 HOMO 和 LUMO 能级. 首先, 为了保证电子 顺利的从给体转移到受体, 并且尽可能的减少转移过程 中的能量损失, 给受体材料的 LUMO 能级差应该在 $0.3 \sim 0.5 \mathrm{eV}$ 之间 ${ }^{[29]}$; 另外, 给体材料的 HOMO 能级应 低于 $-5.2 \mathrm{eV}^{[30]}$, 以保证材料的空气稳定性和器件较高 的 $V_{\mathrm{oc}}$. 现阶段, 人们在设计分子时, 一般选择具有较高 氧化电位单元(如噻吩、三苯胺等)作为给电子基团. (4) 给体材料应具有较高的空穴迁移率以加速电荷传输, 从 而降低正负电荷的复合, 提高器件的光电转换效率. 通 过对小分子给体材料的综述, 我们对于构建高迁移率的 D-A 型小分子提出以下建议: (i)选择具有高共平面性的 稠环基团或齐聚噻吩作为给电子基团, 从而保证分子的 共平面性. (ii)选择吸电子能力适中的单元作为吸电子基 团(如 $\mathrm{TB}$ ). 因为太弱的吸电子基团不利于分子吸收光 谱的拓宽, 而过强的吸电子能力则不利于电子从给体材 料到受体材料的转移 ${ }^{[6]}$. (5)给受体之间应具有较好的相 容性, 即活性层应具有理想的相分离尺寸, 否则激子就 会在达到其扩散长度的最大值前损失掉 ${ }^{[26]}$. 从目前来 看, 设计并合成具有自组装性能的 D-A 型有机小分子是 实现这一目标的有效途径之一 ${ }^{[13,15,51,58]}$.

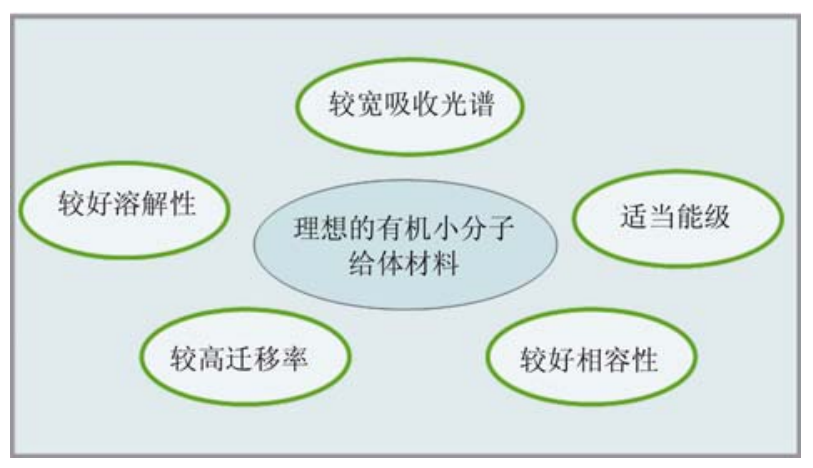

图 1 理想有机小分子给体材料的特点

Figure 1 Characteristics of the ideal organic small molecule donor materials

通过本文的综述, 我们对于未来小分子的发展方向 进行以下几个方面的展望: (1)从分子结构的角度来说, 星型分子较线型分子具有更宽更强的吸收光谱、更高的 空穴迁移率以及更好的成膜性, 其光电转换效率较线型 分子更高. 因此, 构建新的星型给受体分子是未来有机 小分子给体材料发展的趋势之一. (2)从器件制备的角度 来说, 由于有机小分子的成膜性较差, 器件的 $\mathrm{FF}$ 普遍 较低; 所以具有自组装性能的有机小分子可以很好地改
善活性层的表面形貌和相分离尺寸, 从而实现器件 $\mathrm{FF}$ 和性能的提高. 因此, 设计并合成具有自组装性能的 D-A 型有机小分子是有机小分子体异质结太阳能电池 领域的一大热点. (3)从吸收太阳光子的角度上来说, 基 于染料的 D-A 型小分子展现了极高的摩尔吸光系数, 不 仅如此, 经过器件制备方面的优化, 其光电转换效率最 高可达 $5.5 \%$. 因此, 构建高摩尔吸光系数染料分子是提 高有机小分子体异质结太阳能电池光电转换效率的有 效途径之一.

在此我们需要强调的是, 有时器件的光电转换效率 并不一定就能反映出给体材料的真实性能. 这是因为影 响器件光电转换效率的因素是多方面的, 除了材料本身 的性质，还包括给体材料和受体材料之间的比例、不同 的溶剂的使用、退火的时间和温度、活性层的厚度、设 备的配置以及 PEDOT 的导电性等 ${ }^{[6]}$, 而一个高效率的 器件应该是这些最优条件的有效结合. 因此, 在我们合 成出给体材料后, 一定要进行细致的优化, 反复的实验, 这样才能真正实现材料自身的价值.

总的说来，有机小分子太阳能电池仍处于其发展的 初级阶段, 人们仍然在不断地设计和寻找结构新颖、高 性能的 D-A 型有机共轭小分子, 以实现有机体异质结太 阳能电池的商业化, 并通过器件制备和优化不断推动有 机小分子太阳能电池的发展. 在过去短短几年的时间, 有机小分子体异质结太阳能电池的光电转换效率已经 高达 $6.7 \%$, 距离 $10 \%$ 的目标也越来越近. 基于有机小分 子体异质结太阳能电池众多的优点和发展的速度, 我们 有理由相信, 在不久的将来, 有机小分子太阳能电池一 定会走进百姓的日常生活.

\section{References}

[1] Green, M. A.; Emery, K.; Hishikawa, Y.; Warta, W. Prog. Photovoltaics 2008, 16, 61.

[2] Gunes, S.; Neugebauer, H.; Sariciftci, N. S. Chem. Rev. 2007, 107, 1324.

[3] Bungaard, E.; Krebs, F. C. Sol. Energy Mater. Sol. Cells 2007, 91, 954.

[4] Brabec, C. J. Sol. Energy Mater. Sol. Cells 2004, 83, 273.

[5] Chen, H. Y.; Hou, J. H.; Zhang, S. Q.; Liang, Y. Y.; Yang, G. W.; Yang, Y.; Yu, L. P.; Wu, Y.; Li, G. Nat. Photonics 2009, 3, 649.

[6] Li, Y. W.; Guo, Q.; Li, Z. F.; Pei, J. N.; Tian, W. J. Energy Environ. Sci. 2010, 3, 1427.

[7] Gustafsson, G.; Gao, Y.; Treacy, G. M.; Klavetter, F.; Colaneri, N.; Heeger, A. J. Nature 1992, 357, 477.

[8] Roncali, J.; Frere, P.; Blanchard, P.; Bettignies, R.; Turbiez, M.; Roquet, S.; Leriche, P.; Nicolas, Y. Thin Solid Films 2006, 511/512, 567.

[9] Sun, X. B.; Zhou, Y. H.; Wu, W. C.; Liu, Y. Q.; Tian, W. J.; Yu, G.; Qiu, W. F.; Chen, S. Y.; Zhu, D. B. J. Phys. Chem. B 2006, 110, 7702 .

[10] (a) Roquet, S.; Cravino, A.; Leriche, P.; Alévêque, O.; Frère, P.; Roncali, J. J. Am. Chem. Soc. 2006, 128, 3459. 
(b) Ripaud, E.; Rousseau, T.; Leriche, P.; Roncali, J. Adv. Energy Mater. 2011, 1, 540

[11] Lloyd, M. T.; Anthony, J. E.; Malliaras, G. G. Mater. Today 2007, 10, 34.

[12] Rand, B. P.; Genoe, J.; Heremans, P.; Poortmans, J. Prog. Photovolt.: Res. Appl. 2007, 15, 659.

[13] Walker, B.; Tamayo, A. B.; Dang, X. Dung.; Zalar, P.; Seo, J. H.; Garcia, A.; Tantiwiwat, M.; Nguyen, T. Q. Adv. Funct. Mater. 2009, 19, 1.

[14] Shang, H, X.; Fan, H, J.; Liu, Y.; Hu, W, P.; Li. Y. F.; Zhan, X. W. Adv. Mater. 2011, 23, 1554.

[15] Wei, G, D.; Wang, S, Y.; Sun, K.; Thompson, M, E.; Forrest S, R. Adv. Energy Mater. 2011, 1, 184.

[16] Tang, K.; Liang, M.; Liu, Y. K.; Sun, Z.; Xue, S. Chin. J. Chem. 2011, 29, 89.

[17] Li, J.; Wu, W. J.; He, J. X. Acta Chim. Sinica 2010, 68(24), 2551 (in Chinese). (李晶, 武文俊, 贺锦香, 化学学报, 2010, 68(24), 2551.)

[18] Zhang, T. H.; Pu, L. Y.; Zhao, J. L.; Xu, Z.; Yang, L.; Liu, X. Z.; Ju, S. T. Chin. J. Org. Chem. 2011, 31, 260 (in Chinese). (张天慧, 朴玲钜, 赵谡玲, 徐征, 杨磊, 刘祥志, 鞠思婷, 有机 化学, 2011, 31, 260.)

[19] Wang, Z. Y.; Wang, R. Y.; Fu, N. Y. Chin. J. Org. Chem. 2011, 31, 415 (in Chinese). (王振宇, 王如勇, 傅南雁, 有机化学, 2011, 31, 415.)

[20] Sun, Y. M.; Welch, G. C.; Leong, W. L.; Takacs, C. J.; Bazan, G. C.; Heeger, A. J. Nat. Mater. 2012, 11, 44.

[21] Kato, S. I.; Matsumoto, T.; Shigeiwa, M.; Gorohmaru, H.; Maeda, S.; Ishi-i, T.; Shuntaro Mataka, M. Chem. Eur. J. 2006, 12, 2303.

[22] Liu, J.; Bu, L. J.; Dong, J. P.; Zhou, Q. G.; Geng, Y. H.; Ma, D. G.; Wang, L. X.; Jing, X. B.; Wang, F. S. J. Mater. Chem. 2007, 17, 2832.

[23] Wen, S. P.; Pei, J. N.; Zhou, Y. H.; Li, P. F.; Xue, L. L.; Li, Y. W.; Xu, B.; Tian, W. J. Macromolecules 2009, 42, 4977.

[24] He, C.; He, Q. G.; He, Y. J.; Li, Y. F.; Bai, F. L.; Yang, C. H.; Ding, Y. Q.; Wang, L. X.; Ye. J. P. Sol. Energy Mater. Sol. Cells 2006, 90, 1815.

[25] Shang, H. X.; Fan, H. J.; Shi, Q. Q.; Li, S.; Li, Y. F.; Zhan X. W. Sol. Energy Mater. Sol. Cells 2010, 94, 457.

[26] Deng, D.; Yang, Y.; Zhang, J.; He, C.; Zhang, M. J.; Zhang, Z. G.; Zhang, Z. J.; Li, Y. F. Org. Electron. 2011, 12, 614.

[27] Wu, G. L.; Zhao, G. J.; He, C.; Zhang, J.; He, Q. G.; Chen, X. M.; Li, Y. F. Sol. Energy Mater. Sol. Cells 2009, 93, 108.

[28] He, C.; He, Q. G.; Yi, Y. P.; Wu, G. L.; Yang, C.; Bai, F. L.; Shuai, Z. G.; Li, Y. F. J. Mater. Chem. 2008, 18, 4085.

[29] Zhang, J.; Yang, Y.; He, C.; He, Y. J.; Zhao, G. J.; Li, Y. F. Macromolecules 2009, 42, 7619.

[30] Li, W. W.; Du, C.; Li, F. H.; Zhou, Y.; Fahlman, M.; Bo, Z. S.; Zhang, F. L. Chem. Mater. 2009, 21, 5327.

[31] Hide, F.; Greenwald, Y.; Wudl, F.; Heeger, A. J. Synth. Met. 1997, $85,1255$.

[32] Halls, J. J. M.; Walsh, C. A.; Greenham, N. C.; Marseglla, E. A.; Friend, R. H.; Moratti, S. C.; Holmes, A. B. Nature 1995, 376, 498.

[33] (a) Peng, Q.; Park, K.; Lin, T.; Durstock, M.; Dai, L. J. Phys. Chem. B 2008, 112, 2801.

(b) Liu, M. S.; Jiang, X. Z.; Liu, S.; Herguth, P.; Jen, A. K.-Y. Macromolecules 2002, 35, 3532

(c) Li, Y. W.; Xue, L. L.; Li, H.; Li, Z. F.; Xu, B.; Wen, S. P.; Tian, W. J. Macromolecules 2009, 42, 4491.

(d) Li, Y. W.; Li, Z. F.; Wang, C. Y.; Li, H.; Lu, H. G.; Xu, B.; Tian, W. J. J. Polym. Sci., Part A: Polym. Chem. 2010, 48, 2765.

[34] (a) Li, Z. F.; Pei, J. N.; Li, Y. W.; Xu, B.; Deng, M.; Liu, Z. Y.; Li,
H.; Lu, H. G.; Li, Q.; Tian, W. J. J. Phys. Chem. C 2010, 114, 18270 .

(b) Li, Z. F.; Dong, Q. F.; Li, Y. W.; Xu, B.; Deng, M.; Pei, J. N.; Zhang, J, B.; Chen, F. P.; Wen, S. P.; Gao, Y. J.; Tian, W. J. J. Mater. Chem. 2011, 21, 2159.

[35] Mikroyannidisa, J. A.; Stylianakis, M. M.; Dong, Q. F.; Zhou, Y. H.; Tian, W. J. Synth. Met. 2009, 159, 1471

[36] Mikroyannidis, J. A.; Kabanakis, A. N.; Kumar, A.; Sharma, S. S.; Vijay, Y. K.; Sharma, G. D. Langmuir 2010, 26(15), 12909.

[37] Mikroyannidis, J. A.; Sharma, S. S.; Kumar, A.; Vijay, Y. K.; Sharma, G. D. Appl. Mater. Interfaces 2010, 2(1), 270.

[38] (a) Zhang, W. F.; Tse, S. C.; Lu, J. P.; Tao, Y.; Wong, M. S. J. Mater. Chem. 2010, 20, 2182.

(b) Zhang, W. F.; Ng, G. M.; Tam, H. L.; Wong, M. S.; Zhu, F. R. J. Polym. Sci., Part A: Polym. Chem. 2011, 49, 1865.

[39] Zhang, J.; Deng, D.; He, C.; He, Y. J.; Zhang, M. J.; Zhang, Z. G.; Zhang, Z. J.; Li, Y. F. Chem. Mater. 2011, 23, 817.

[40] Liu, Y. S.; Zhou, J. Y.; Wan, X. J.; Chen, Y. S. Tetrahedron 2009, $65,5209$.

[41] Liu, Y. S.; Wan, X. J.; Yin, B.; Zhou, J. Y.; Long, G. K.; Yin, S. G.; Chen, Y. S. J. Mater. Chem. 2010, 20, 2464.

[42] Yin, B.; Yang, L. Y.; Liu, Y. S.; Chen, Y. S.; Qi, Q. J.; Zhang, F. L.; Yin, S. G. Appl. Phys. Lett. 2010, 97, 023303.

[43] Liu, Y. S.; Wan, X. J.; Wang, F.; Zhou, J. Y.; Long, G. K.; Tian, J. G.; You, J. B.; Yang, Y.; Chen, Y. S. Adv. Energy Mater. 2011, 1, 771.

[44] He, C.; He, Q. G.; Yang, X. D.; Wu, G. L.; Yang, C. H.; Bai, F. L.; Shuai, Z. G.; Wang, L. X.; Li, Y. F. J. Phys. Chem. C 2007, 111, 8661 .

[45] Zhao, G. J.; Wu, G. L.; He, C.; Bai, F. Q.; Xi, H. X.; Zhang, H. X.; Li, Y. F. J. Phys. Chem. C 2009, 113, 2636.

[46] Zhang, J.; Wu, G. L.; He, C.; Deng, D.; Li, Y. F. J. Mater. Chem. 2011, 21, 3768.

[47] Xue, L. L.; He, J. T.; Gu, X.; Yang, Z. F.; Xu, B.; Tian, W. J. J. Phys. Chem. C 2009, 113, 12911.

[48] Li, Z. F.; Dong, Q. F.; Xu, B.; Li, H.; Wen, S. P.; Pei, J. N.; Yao, S. Y.; Lu, H. G.; Li, P. F.; Tian, W. J. Sol. Energy Mater. Sol. Cells 2011, 98, 2272.

[49] Tamayo, A. B.; Tantiwawat, M.; Walker, B.; Nguyen, T. Q. J. Phys. Chem. C 2008, 112, 15543.

[50] Tamayo, A. B.; Walker, B.; Nguyen, T. Q. J. Phys. Chem. C 2008 , 112, 11545 .

[51] Tamayo, A. B.; Dang, X. D.; Walker, B.; Seo, J.; Kent, T.; Nguyen, T. Q. Appl. Phys. Lett. 2009, 94, 103301.

[52] Mazzio, K. A.; Yuan, M. J.; Okamoto, K.; Luscombe, C. K. ACS Appl. Mater. Interfaces 2011, 3, 271.

[53] Loser, S.; Bruns, C. J.; Miyauchi, H.; Ortiz, R. P.; Facchetti, A.; Stupp, S. I.; Marks, T. J. J. Am. Chem. Soc. 2011, 133, 8142.

[54] Kroneneberg, N. M.; Deppish, M.; Würthner, F.; Ledemann, H. W. A.; Deing, K.; Meerholz, K. Chem. Commun. 2008, 6489.

[55] Rousseau, T.; Cravino, A.; Bura, T.; Ulrich, G.; Ziessel, R.; Roncali, J. Chem. Commun. 2009, 1673.

[56] Rousseau, T.; Cravino, A.; Ripaud, E.; Leriche, P.; Rihn, S.; Nicola, A. D.; Ziesselb, R.; Roncali, J. Chem. Commun. 2010, 46 , 5082 .

[57] Silvestri, F.; Irwin, M. D.; Beverina, L.; Facchetti, A.; Pagani, G. A.; Marks, T. J. J. Am. Chem. Soc. 2008, 130, 17640.

[58] Wei, G, D.; Wang, S, Y.; Renshaw, K.; Thompson, M. E.; Forrest, S. R. ACS Nano 2010, 4, 1927.

[59] Sun, X. B.; Liu, Y. Q.; Xu, X. J.; Yang, C. H.; Yu, G.; Chen, S. Y.; Zhao, Z. H.; Qiu, W. F.; Li, Y. F.; Zhu, D. B. J. Phys. Chem. B 2005, 109, 10786. 
[60] Zhou, Y. H.; Peng, P.; Han, L.; Tian, W. J. Synth. Met. 2007, 126, 464.

[61] Lincker, F.; Delbosc, N.; Bailly, S.; De Betignies, R.; Billon, M.; Pron, A.; Demadrille, R. Adv. Funct. Mater. 2008, 18, 3444.

[62] Li, K. P.; Qu, J. L.; Xu, B.; Zhou, Y. H.; Liu, L. J.; Peng, P.; Tian, W. J. New J. Chem. 2009, 33, 2120.

[63] Mei, J. G.; Graham, K. R.; Stalder, R.; Reynolds, J. R. Org. Lett.
2010, 12, 660 .

[64] An Chen, J. J.; Chen, T. L.; Kim, B. S.; Poulsen, D. A.; Mynar, J. L.; Fréchet, J. M. J.; Ma, B. W. ACS Appl. Mater. Interfaces 2010, 2, 2679.

[65] Cheng, Y. J.; Yang, S. H.; Hsu, C. S. Chem. Rev. 2009, 109, 5868.

[66] Cravino, A.; Schilinsky, P.; Brabec, C. J. Adv. Funct. Mater. 2007, $17,3906$.

(Zhao, C.) 